\title{
Harvesting and transport operations to optimise biomass supply chain and industrial biorefinery processes
}

\author{
Robert Matindi ${ }^{\mathrm{a}}$, Mahmoud Masoud ${ }^{\mathrm{b}}$, Phil Hobson ${ }^{\mathrm{a}}$, Geoff Kent ${ }^{\mathrm{a}}$ and Shi Qiang Liu ${ }^{\mathrm{c}}$
}

${ }^{a}$ School of Chemistry, Physics and Mechanical Engineering Science and Engineering Faculty, Brisbane Qld 4001 Australia

${ }^{b}$ School of Mathematical Sciences, Queensland University of Technology, 2 George St, Brisbane Qld 4001 Australia

${ }^{c}$ School of Economics and Management, Fuzhou University, Fuzhou, 350108, China

\section{CH R O N I C L E}

\section{Article history:}

Received March 182017

Received in Revised Format

August 252017

Accepted Septmeber 12017

Available online

September 12017

Keywords:

Bio-refinery

Cane transport

Cane harvesting

Constraint programming \begin{abstract}
A B S T R A C T
In Australia, Bioenergy plays an important role in modern power systems, where many biomass resources provide greenhouse gas neutral and electricity at a variety of scales. By 2050 , the Biomass energy is projected to have a $40-50 \%$ share as an alternative source of energy. In addition to conversion of biomass, barriers and uncertainties in the production, supply may hinder biomass energy development. The sugarcane is an essential ingredient in the production of Bioenergy, across the whole spectrum ranging from the first generation to second generation, e.g., production of energy from the lignocellulosic component of the sugarcane initially regarded as waste (bagasse and cane residue). Sustainable recovery of the Lignocellulosic component of sugarcane from the field through a structured process is largely unknown and associated with high capital outlay that have stifled the growth of bioenergy sector. In this context, this paper develops a new scheduler to optimise the recovery of lignocellulosic component of sugarcane and cane, transport and harvest systems with reducing the associated costs and operational time. An Optimisation Algorithm called Limited Discrepancy Search has been adapted and integrated with the developed scheduling transport algorithms. The developed algorithms are formulated and coded by Optimization Programming Language (OPL) to obtain the optimised cane and cane residues transport schedules. Computational experiments demonstrate that high-quality solutions are obtainable for industry-scale instances. To provide insightful decisions, sensitivity analysis is conducted in terms of different scenarios and criteria.
\end{abstract}

\section{Introduction}

\subsection{Backgroud}

The key technical and financial issues affecting the viability of bioenergy projects relate to low energy density and the dispersed nature of biomass feedstock (Hobson, 2009 p2357). Most biomass conversion technologies, particularly those associated with second generation bioproducts production ideally from the lignocellulosic component of the biomass in question, have high associated capital cost and thus the financial viability of these second generation technologies for power and bioproducts productions is dependent on achieving sufficient economies of scale and high utilisation associated with abundant feedstock supply (Meyer et al., 2012 p2359).

* Corresponding author

E-mail: robert.matindi@qut.edu.au (R. Matindi)

(C) 2018 Growing Science Ltd. All rights reserved. doi: $10.5267 /$ j.ijiec.2017.9.001 
One way of overcoming the inherent challenges of biomass (low density and spatial dispersion) is through the energy densification processes, among them raking and baling of cane residue, and retrofitting it conveyance (transport) to that of the cane transport system.

This in essence will take the advantage of the existing sugarcane transport infrastructure that is well established and understood, with minimal or no change in the existing set up (sidings, bins, trailers, locos and trucks).

With this innovative approach, two objectives will be accomplished, which are standardisation and the optimisation of equipment use. For instance, baling as residues recovery method will increase the density and transform the biomass into uniform units (bales).

Studies indicate that standardization and optimization lead to a reduction in residue recovery and transportation costs (Hobson \& Wright, 2002 p2358). Approximately $67 \%$ of the sugarcane trash from the field can be recovered when baling (Hassuani, 2005 p2355). This, combined with approximately $20 \%$ of the trash that is not separated from the sugarcane in the harvester, results in $87 \%$ of the trash reaching the mill (Hess et al., 2007 p2356) detailed the logistical data and cost per dry tonne for the baling unit operation, including capital, maintenance, ownership unit costs required for rectangular bales $(1.2 \mathrm{~m} \times 1.2 \mathrm{~m} \times 2.4 \mathrm{~m})$, and from their analysis, $30-40 \%$ of biomass cost can be saved by simply densifying energy content into a standardised unit relative to its loose state.

Parallel approaches similar to cane supply chain, can be drawn and adopted for use in cane residue recovery (lignocellulosic supply chain for bioenergy production) in terms of unit operations, and potential areas for improvement and or optimisation. This in effect will entail invoking methodologies, approaches and strategies that had been successfully applied before albeit in conventional cane supply chain. One of such approaches, for instance, is in scheduling and management. The scheduling and management of cane supply has been shown to improve on operational time with minimal no capital outlay. Schedules when well executed can greatly improve operational production time without necessarily changing the existing investment portfolio (Masoud et al., 2011 p2348; Thorburn et al., 2006).

\subsection{Literature review}

The key aspects that distinguishes biomass supply chain from the well understood petrochemical supply chain and further analyse the commonality that can be leveraged upon in order to lower the production costs of either bio-products (platform chemicals), or bioenergy outputs, these tools and processes include planning and scheduling frameworks established for logistics activities, aimed at coordinating the use of resource and end to end optimisation of biomass-bio-products supply chain (Chen, 2012 p436; Yue, 2014 p970;).

Some of the distinct features that characterize it are uncertainties of different magnitude ranging from variability in climatic conditions to quality of recovered biomass. Due to the uncertainty aspect plants and in effect biomass are susceptible to adverse weather condition, which consequently has an effect on the overall moisture content (wet weather condition in terms of growing).

From an economic perspective, uncertainty have a direct bearing on total capital cost required per unit of recovered biomass. High moisture content biomass, for instance and based on technology at play (for example bio-gasification) will inevitably necessitate extra unit operation steps of pretreatment to have the biomass into the required state (Drying and ash removal process). This will be invoked in order to meet the strict requirements of a gasifier and other strict environmental regulations in a given jurisdiction. This extra pre-treatment steps increases the cost of recoverable biomass see (Faaij et al., 1997 p387; Henrich et al.,2009 p28; Hobson et al.,1998 p9; Hobson et al., 2003 p60). The other challenge associated with biomass supply chain is that their economic parameters are largely uncertain, due to the wide 
dispersal of biomass across geographical regions, thus making their collection and transport difficult coupled with intrinsic characteristic of biomass and that is their low energy density. These attributes does impact on the overall cost of the recovery process of biomass (Alex et al., 2012 p68; Hobson et al., 2006; Juffs et al., 2006; Meyer et al., 2012).

Other aspects of biomass supply chain that affect the cost of both the final product and the delivered raw biomass is the size and location of the biorefinery. Previous studies have analysed and developed models to study the facility location and biomass supply chain optimisation, this includes (Elms et al., 2010 p547) who studied the scheduling process of multiple feedstock for a biodiesel facility in order to optimise biodiesel production and lower greenhouse gases .

In the (Alex et al., 2012 p68) study a tool was developed and using Mixed Integer Linear program technique determined the optimal potential locations and size of bio refineries in a 9 state region in Mideastern USA.

In this study, it was deduced that the key parameters that affect the optimal sizing and location of a biorefinery are biomass supply source, the transportation distance and cost to the biorefinery, the costs of biomass, the cost of the biofuel produced (Ethanol sale price), and biorefinery costs and capacity .In their analysis a total of 65 locations were identified as optimal with a total of 4.7 Billion Gallon per year (BGY) of ethanol, \$2.99 per gallon assuming the volumetric ethanol excise tax credit.

The other feature of biomass supply chain is that biomass are low energy products, and in order to increase the energy density of biomass, pre-processing of the biomass may be an imperative step based on the transportation distance envisaged.

The location and configuration of such pre-processing facility has a bearing on the eventual cost of such biomass. Bowling et al. (2011) developed a superstructure for determining the optimal location of such a facility, that allows for simultaneous selection of a preferred configuration (centralized or distributed with maximizes profit in the entire value chain.

The modelling process entailed configuration of optimal flow rates that ensure maximum returns in terms of profit, Bowling et al. (2011) study found out that the key determinant on whether to density the biomass or not was the transportation distance and the capital cost of the processing facility based on the technology used for densification.

In the realms of management, biomass supply chain can be beamed into three rays; the strategic, tactical and operational levels. Decisions undertaken in each of those levels have an effect on cost and proper operation of the system. Some of the key strategic decision in biomass supply chain has to do with the storage of biomass in terms of capacity planning, truck scheduling among others.

Scheduling systems and strategies can minimize travel time and consequently the total costs as exemplified in the following studies (Ravula et al., 2008 p314; Mafakheri et al.,2014 p116).

Application of mathematical modelling techniques to bioenergy supply chain have facilitated the understanding, assessment and performance of the same.

The use of deterministic and stochastic mathematical models to optimize forest biomass supply has been studied and analysed. One facet of supply chain that applies have employed those class of techniques is in the scheduling operation.

A study by (Shabani et al., 2013 p299) on truck scheduling and optimization with an objective of minimizing the weighted sum of transportation costs and total operation time found that, these model can accurately capture the bottleneck in a system and produce a practical solution. 
They further used simulated annealing solution technique to solve the truck scheduling problem, and it was found that total cost and working time reduced by $18 \%$ and $15 \%$ respectively.

Simulation technique are other sets of modelling tools that have been employed to study biomass supply chain .Simulation technique known to mimic real life scenarios and thus are ideal in study of logic flow and interactions that are potentially hard to represent mathematically.

Whilst simulation approaches may provide important insights into the operation of bioenergy supply chains, the fundamental structures are not fully understood because biomass supply chains are still evolving when compared to petroleum industry supply chain, and thus for economic ,environmental and energy efficiency improvement to be realized, end to end perspective need to be tapped into (Dunnett et al., 2007 p419).

Siting of the biorefinery is another characteristic of biomass supply chain. Mafakheri et al., (2014) in their analysis found that the choice of a biomass location depended on various factors key among them the type and characteristic of the biomass material.

Identification of the optimal location for both storage and biorefinery refinery facility may help in reducing the cost of the overall supply chain operations, previous studies have shown that co-location of storage facility to the biorefinery or near the processing facility reduces the overall cost of the biomass (Mafakheri et al.,2014 p116).

Models that have been employed to schedule and plan the storage capacity, and location have been analysed and enumerated in previous studies see (Nilsson et al., 2001 p247; Rentizelas et al., 2009 p887; Sokhansanj et al., 2010 p75; Sokhansanj et al., 2002 p347; Vadas et al., 2013 p133; Van Dyken et al., 2010 p1338; van Vliet et al., 2009 p855; Wang et al., 2014 p32).

In (Dunnett et al., 2007 p419) study, a network optimisation framework and integrated tool were developed .These systems linked the upstream and downstream activities ranging from storage scheduling, energy conversion schedules the process of integrating the system resulted in 5-20\% reduction in total cost of biomass supply chain (Mafakheri et al., 2014 p116) thus underpinning the importance of modelling tools that can be leveraged on to improve on process efficiency.

A critical synthesis of biomass-to-energy production shows gaps on some areas in research that are yet to be fully explored. According to Iakovou et al. (2010), the bottlenecks hindering development of bioenergy system are basically the cost of logistics operations. Logistic costs can be disaggregated into component costs that chain together to form the bioenergy supply chain.

Besides the logistic costs, biomass supply chain system suffers from quality and quantity differences, they vary considerably depending on the technology at play, the demands requirement of energy among other factors.

These challenges are further compounded by the uncertainty in their supply, the infancy state of their development, and the overall bioenergy environment. These challenges have a direct bearing on the cost of bioenergy product and thus proper planning and employment of innovative tools to can reduce the negative impact.

\subsection{Innovation and contribution}

While some research and development has been conducted in individual local areas for separate steps in supply chain from the grower to the mill, vertical integration or regional adoption based on priority has not been done for cane trash recovery. The marginal and notional gains accrued from such a process are 
hardly reported or explored. The next section, therefore, explores a potential transport problem that will inevitably be experienced if existing sugarcane infrastructure was to be adopted prima facie for recovery of cane residue.

To conclude this section on routing and scheduling problems, few points are worth highlighting:

1. The size of the optimization problem in all the types of routing and scheduling problem increases much quicker than the rate at which the size of the actual problem increases. For example, under unlimited train/truck capacity, if there are three nodes (sidings), there is just one feasible route (path) according to the rule of number of routes (paths) $(\boldsymbol{n}-\mathbf{1}) ! / 2$ routes or trips for $n$ nodes (sidings). As a result, the problem in reality will be more complicated under limited train/truck capacity. The impact of this property is that even if exact solution techniques exist, many are rendered useless in practical situations because of the excessive time requirements.

2. All problems deal with discrete quantities, which are difficult to deal with using traditional techniques.

3. From practical standpoints, the optimal is not necessarily one which has to be obtained; solutions which are good (i.e., close to the optimal) are equally important provided they can be obtained quickly. Therefore, unsurprisingly, heuristic techniques (which typically guarantee near-optimal solutions) continue to play an important role as viable solution techniques for these problems.

\section{The Transport Rail/Route Scheduling Problem}

There are two major classes of cane transport problems, namely the truck routing problem and the train railing problem. The sheer number of different possible paths and various different constraints representing several resource limitations make the development of such a transport system difficult. The $\mathrm{road} / \mathrm{rail}$ scheduling problem refers to all problems where optimal closed loop paths which touch different points of interest are to be determined. There may be one or more trains or trucks. Generally the points of interest are referred to as nodes (siding or conjunction); further, the start and end nodes of a path are the same and often referred to as the depot (mill). Train/truck scheduling approach has been used to optimize train/truck transport systems. The problem is that given a set of routes (or rail tracks), one needs to develop schedules for trains or trucks arrivals and departures at all the sidings of the network. A good or efficient schedule is one which minimizes the total operating times of trains or trucks with minimal waiting time of harvesters and mill. The harvesters are waiting for empty bins at sidings and mill for full bins under a set of resource and service related constraints. The total waiting time of harvesters and mill have two components: (i) the total initial waiting time (IWT) of harvesters and mill, which is the sum of the waiting times of all the harvesters and mill at their point of origin (time 0 of starting the system), and (ii) the total transfer time (TT), which is the sum of the transfer times of all the transferring empty and full bins between harvesters and mill. The resource and service related constraints are:

a. Limited fleet size: only a fixed number of trucks or locomotives are available for operating on the different routes.

b. Limited Trucks or locomotives capacity: each truck or locomotive has a finite capacity

c. Shunting time bounds: Trucks or locomotives cannot stop for a very short or a very long time at a siding/pad.

d. Policy headway: on a given route, a minimum frequency needs to be maintained. 
e. Maximum transfer time (cane age): no full bins should have to wait too long for a transfer (less than 16 hours after harvesting is the recommended standard for the cut cane to retain its integrity).

Under the previous limitations, the historical data show that sugarcane transportation between harvesters and mills satisfy delays in delivering the cane as shown in Fig. 1(a). Delivering the crop 16 hours or more after harvest affects the crop quality and reduces the sugar rates. Optimizing the delivery and collection times to siding and mill will reduce the delays.

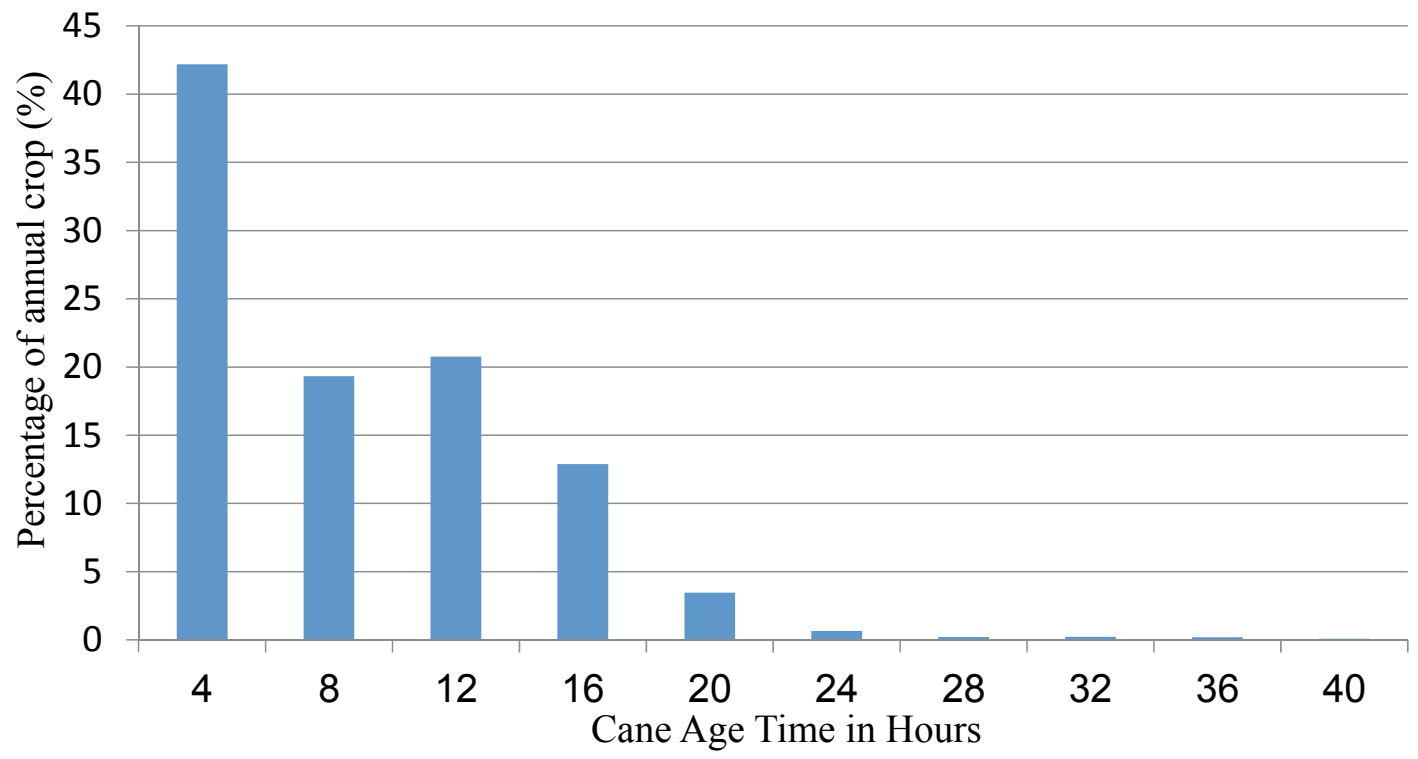

Fig. 1(a). Delay before cane is picked up from siding (hours) to mill

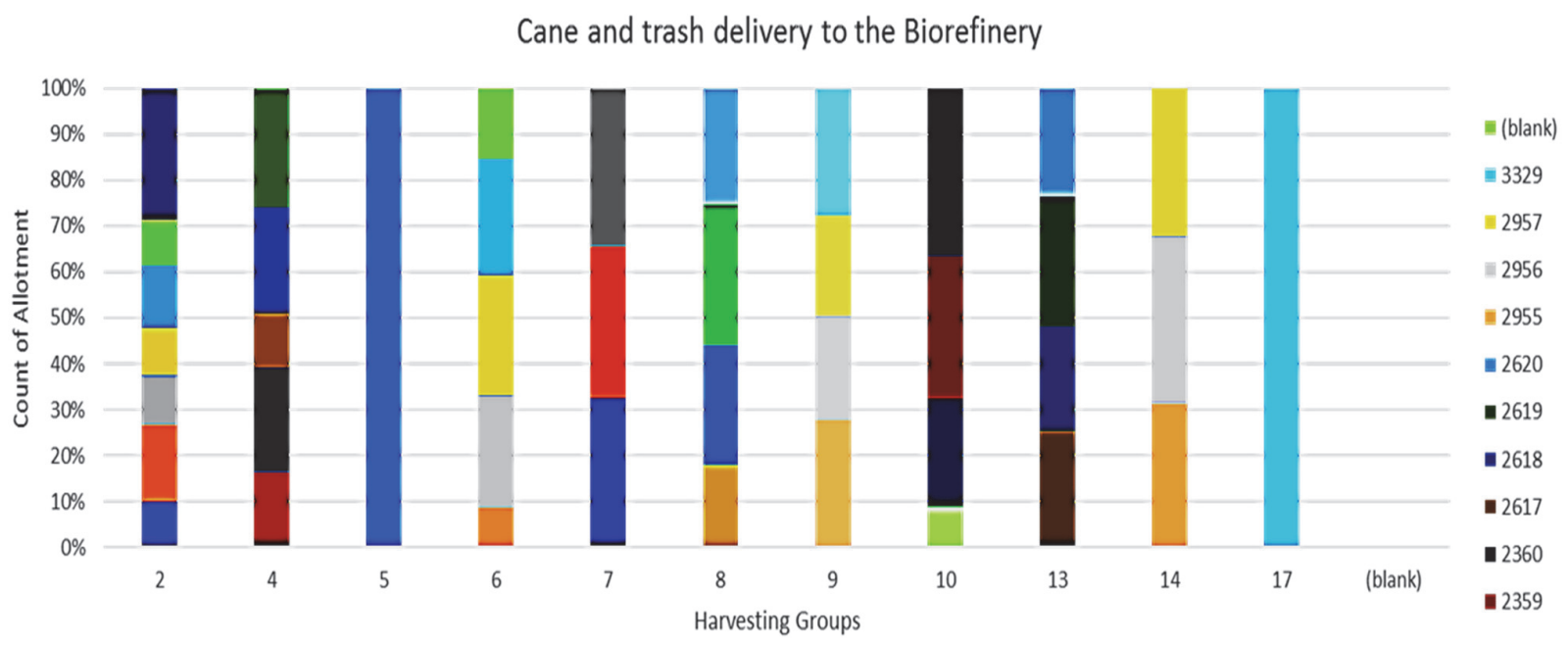

Fig. 1(b). A simulation of the flow of biomass from various harvesting groups to the factory / /biorefinery

Fig. 1(b), shows the flow of various allotments from the field to the biorefinery from various harvesting groups (biomass sources), the above flow underscores the need for proper management and scheduling of biomass through various allotments, to among other things avoid oversupply of biomass beyond the biorefinery capacity, or undersupply which may result to suboptimal use of the biorefinery. Some of the features related to the train/truck scheduling problem which the proposed methodology designed to solve the problem must be capable of handling are: 
a. Arrival time of a truck/ train at one siding/pad is dependent on the arrival time of the truck/ train at the previous stop.

b. Arrival times of trains/trucks at a siding are generally not exactly as per the schedule. Arrival times are generally randomly distributed around the scheduled arrival times. Since arrival times are not exactly as per schedule, departure times are also not exactly as per schedule.

c. If demand for a route is very high during a particular period, then the queue developed for that route at the siding may not be cleared entirely by the next truck in the route due to limited train/truck capacity. In such cases, the formation and the dissipation of the queue must be tracked so that realistic values for the waiting times and transfer times can be obtained.

d. The arrival patterns of full bins at sidings/pads may vary widely. Sidings/pads which primarily have cane and trash in effect may see a surge in bins arrivals just before the arrival time of train/truck, consequently leading to stoppage of harvesting process until sufficient bins have been towed away and empty ones loaded. Synchronizing such operations real time makes that scheduling aspect of the operation NP difficult.

Therefore, given the combinatorial nature of the problem, the number of variables (especially the integer ones) and the number of constraints increase at a fast rate with the increase in number of routes and fleet size. Further, given the restricted ability of traditional optimization methods to handle MINLP problems, it is seen that even extremely small problems (for example, three routes and ten trains/trucks in each route/rail) cannot be solved within a reasonable time frame using traditional methods. As in the case of transport scheduling problem, most of the earlier work on transport scheduling with transfer considerations (e.g. Bookbinder \& Desilets, p2360; Rapp \& Gehner, 1967 p2361) rely on heuristics and user intervention at various stages of the solution process. Further, that MP formulations make two important simplifying assumptions of unlimited train/truck capacity or unlimited number of truck/train, or deterministic arrival times.

In Australia, transport systems play a vital role in the raw sugar production process and, to a large extent, bioenergy production by transporting the sugarcane crop between farms and mills. Most of the cane transport system uses a specific schedule of runs in order to meet the requirements of various industry stakeholders, ideally the mill and the harvesting contractor (Masoud et al., 2011 p2348; Masoud et al., 2012 p2349). Some of the methods used to transport cane entails rail only, road only, or a mixture of the two modes (rail and road) (Pernase \& Pekol, 2012 p2362).

In 2013, 87 per cent of sugarcane was transported to mills by cane railway, a direct road transport network is the next most significant way to transport 8 per cent of sugar cane, and a further 5 per cent was transported by a combination of road and cane (Masoud et al., 2015 p2363;(Mitchell, 2015 p2364))). More cane lands are being established in remote locations and due to the high capital cost of establishing a railway, the amount of road transport to mills is growing, which various studies can be optimised to match up with a biorefinery facility (Nguyen, 1996 p2367). Road systems between harvesting areas and pads use small trucks (Infield Haul-out unit) with one bin fleet size ( 8 tonnes or 5 tonnes), while the road system (factory road system) from pads and mill use big truck with 2 bins (B-Double) with fleet size of 20 tonnes per bin (Higgins, 2006 p2368) see Fig. 2.

The sugarcane and cane residue transport system is very complex due to the need to effectively satisfy the requirements of several harvesters at different locations and keep a continuous supply of cane for mill processing, given limited resources of train /truck, trailer and bin fleet. Scheduling of sugarcane using a rail systems in Australia is complicated by the fact that cane railway networks have single tracks with few dedicated passing loops, requiring the passing of trains to be addressed. There are many branches where trains may wait to allow other trains to pass. Some sidings may also act as passing loops when not in use. The challenge is further compounded by the simultaneous recovery of cane residues which, in effect, means a near doubling of the numbers of bins to be railed on an already constrained system in 
order to fulfil the daily requirements of a biorefinery. Such a problem will require a seamless scheduling system. Scheduling problems in single track railway systems have proven difficult to solve and there have been many studies to improve system performance.

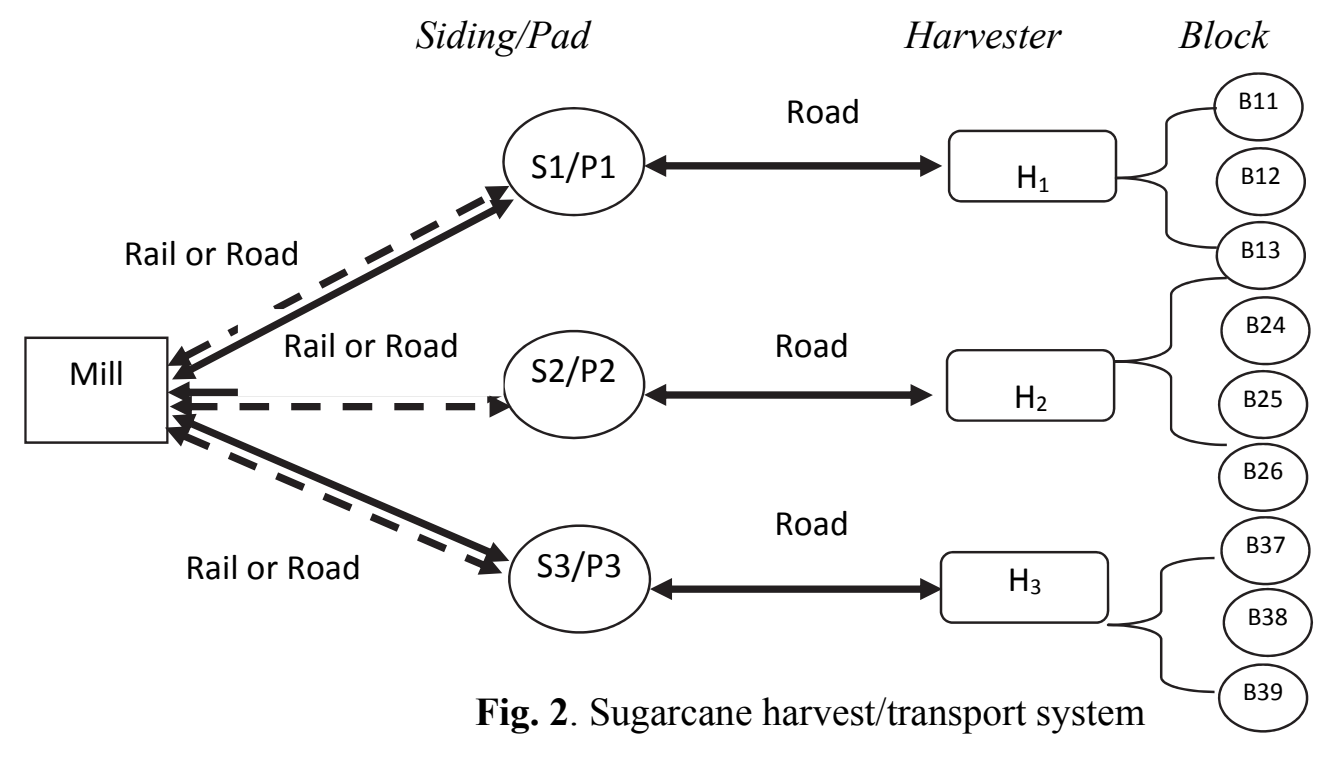

\section{Solution Approach}

Many strategies are followed to find the solution. Search trees have been explored in past studies (Goloboff, 1999 p2369 (Van Hentenryck, 2000 p2370) (Jain, 1999 p2371))). Where most of them uses search strategies as prime methods when using parallel branch and bound technique to solve combinatorial optimisation problems. The main advantage of these methods is in obtaining the optimal solution for many NP-hard problems but on the other hand, using some of these techniques individually is time consuming coupled with expensive resource requirements in terms of memory footprint that is required to solve large scale problems.

The framework of the proposed methodology therefore depends on integrating optimisation methods such as Limited Discrepancy Search (LDS) with transport scheduling algorithms to obtain a good solution but not necessarily optimal. The LDS will be used to develop the proposed main paths of locomotives or trucks without transport constraints and then use the transport methods to construct the practical constraints that are valid for real cases studies. Fig. 3 shows the main proposed solution approach for the scheduling transport problem. ExtendSIM software (Simulation software) was used to run un-scheduled approach to the transport problem, while the ILOG-OPL software was used to in development of scheduling the delivery and collection processes using scheduling algorithms as stipulated in Fig. 3(a).

\section{a. $\quad$ Adapted Limited Discrepancy Search}

Limited Discrepancy Search (LDS) method depends on building the search tree by a good heuristics (Harvey, 1995 p2365). The first leaf which is visited is likely to be a solution. If this leaf is not a solution, it is likely the number of mistakes along the path from the root to this leaf is a small number. Then, the next leaf nodes will be visited which have paths from the root that differ only in one choice from the initial path. This process continues by visiting the leaves which have a higher discrepancy from the initial path. For a discrepancy $d>0, L D S$ visits leaves with discrepancy less than $d$, so leaves are visited many times. This can be avoided by keeping track of the remaining depth to be searched. Let the discrepancy of a node $v$ be $c$, and the length of a path from $v$ to a leaf be 1 , then we consider descendants which is the discrepancy between $d-1$ and $d$. This search strategy is called improved limited 
discrepancy search. It is noted that, DFS and $L D S$ are complete search strategies that are not redundant where these techniques have to visit all paths from the root to a leaf exactly once.

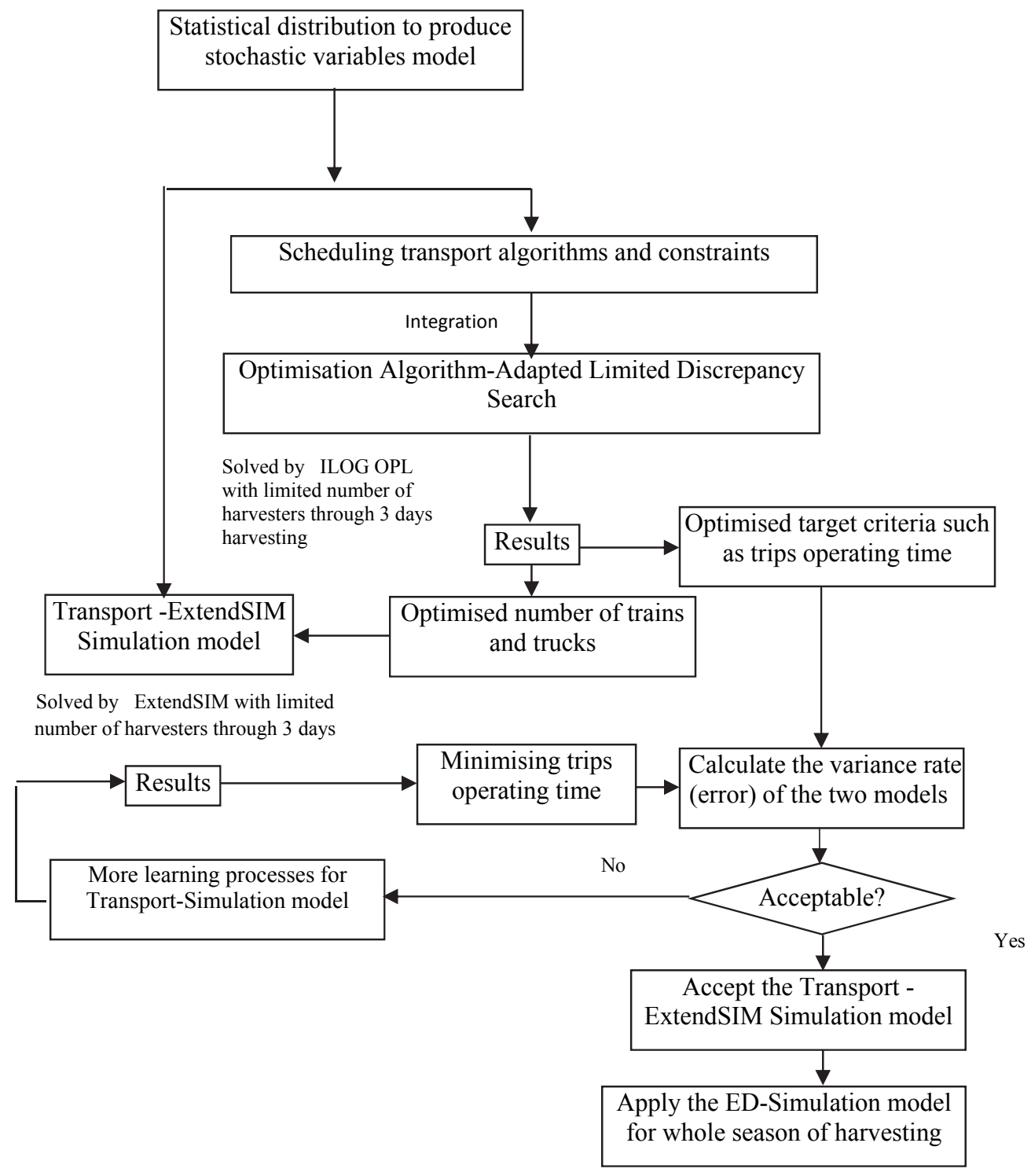

Fig. 3(a). The framework of the integrated Optimisation-Simulation approach for the transport system

The $L D S$ has been adapted in this paper to be used to optimise the delivery and collection at all nodes (mill, siding and biorefinery) through a transport network. Formally, let $\gamma_{0}$ be a node with ordered descendants $\gamma_{1}, \gamma_{2} \ldots \gamma_{k}$. The discrepancy of $\gamma_{j}$ is the discrepancy of $\gamma_{0}+j-1$ for $j=1,2, \ldots, k$ and the discrepancy of the root node is 0 . The main steps of $L D S$ are listed as follows:

Step 1: Let the level of discrepancy be $d=0$ starts at the root node.

Step 2: Proceeds by descending to its first descendant $\gamma_{1}$, which its discrepancy is not higher than $d$.

Step 3: This process continues until we reach a leaf.

Step 4: Backtrack to the parent of the leaf and the descent to its next existing descendant, which has a discrepancy that is not higher than $k$.

Step 5: This process continues until we are back at the root node and when all its descendants that have a discrepancy that is not higher than $k$ have been visited.

Step 6: Set $d=d+1$ and repeat this process until we are back at the root node and all its descendants have been visited. 


\subsection{Transport Scheduling Algorithms}

The cane transport system includes two main stages; transporting cane from harvester's pad to nearest siding by trucks (Infield transport system) and transporting the cane from siding to mill by trains or roads (Factory transport System). Siding area has a limited capacity; as a result full bins must be collected immediately from siding by trains or trucks before the siding capacity get exhausted in terms of having bins fully filled by the harvester (with harvested cane), or having zero empty bins at the siding thus stopping the harvesting process. Delivery and collection times at siding must be optimised where collecting time for full bins from siding should be after the deliveries of empty bins to the siding by trucks/trains. This process should work continuously to avoid any blocking issues for siding or interruption in harvester or mill work or the biorefinery. Fig. 3 shows rail and road system to transport cane from harvester area (siding/pad) to mill within the siding area. In this scenario, two harvesters have been assigned to one pad, where according to the industry practice one pad can serve one or more harvesters sequentially.

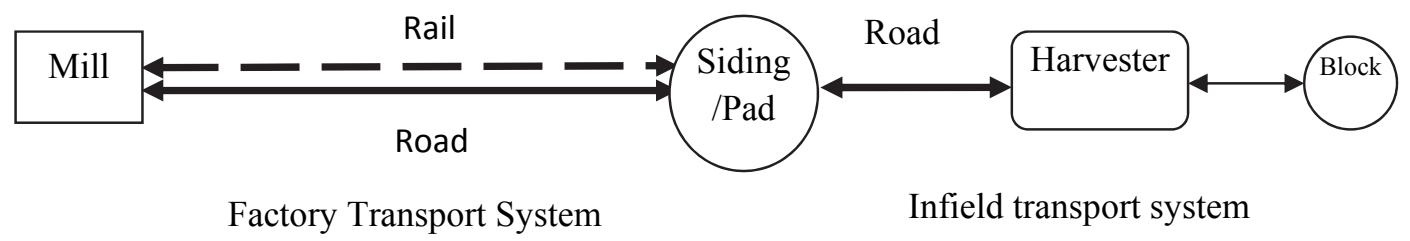

Fig. 3(b). Integrating Rail and Road systems with assigning two harvesters to one pad

\subsubsection{Factory Rail Scheduling Algorithm (RSA)}

The rail systems play an important role in transporting harvested sugarcane from siding/pad points to mill. In Figure 4, the rail network has been used to deliver empty bins to siding/pad and full bins to mill, and on the another side, collecting empty bins from mill and full bins from siding/pad. The algorithm $R S A$ integrates the infield transport system with factory rail system. The rail transport system uses the trains with 120 bins for each, while the infield transport system uses truck with one bin fleet size (8 tonnes or 5 tonnes).

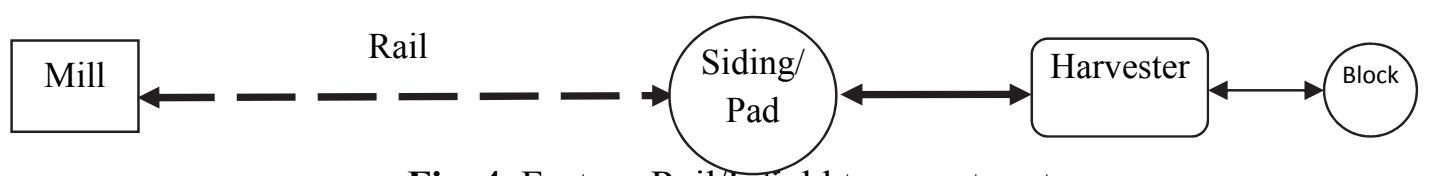

Fig. 4. Factory Rail/Infield transport systems

The Rail Scheduling algorithm (RSA) has been developed to optimise the deliver and collection times through the rail network at siding/pad points and Mill. The main procedures of RSA algorithm has been detailed below:

Select Train $r ; r \in R$

Set the train capacity $e_{r}$ and $f_{r}$

Select run $n ; n \in N_{r}$

Select siding $s ;$ s $\in$ S $\quad$ // step 3

Set the siding capacity; $y_{S}$

Set the siding Allotment; $A_{s}$

Sum delivers to siding $s$ by train $r$ at run $n ; \alpha_{s} / /$ at the beginning of the system $\alpha_{s}=0$

Sum Collects from siding s by train $r$ at run $n ; B_{s}$ //at the beginning of the system $B_{s}=0$

If $o^{\prime} \leq o$ then $\left(o \& o^{\prime}\right.$ are two operations are implemented on same siding during same run outbound direction

$$
\text { If }\left\{\operatorname{sum}\left(o^{-} \text {in operations }\right) \alpha_{\text {rnos }}\right\} \leq A_{s} \text { then }
$$




$$
\begin{aligned}
& \alpha_{r n o}{ }^{\prime} \leq e_{r}
\end{aligned}
$$

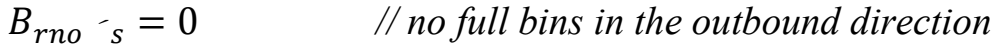

$$
\begin{aligned}
& t_{r \text { los }} \geq\left(\alpha_{\text {rnos }} / \text { Hrate }_{\mathrm{S}}\right)+\text { Hstart }_{\mathrm{S}} \\
& t_{r+1 \text { nos }} \geq t_{\text {rnos }}+\left(\alpha_{\text {rnos }} / \text { Hrate }_{\mathrm{s}}\right)+\text { Hstart }_{\mathrm{s}} \\
& \alpha_{\text {rno }{ }^{\prime} s}+B_{\text {rno }{ }^{\prime} s} \leq y_{s} \\
& \alpha_{s}=\alpha_{s}+\alpha_{r n o}{ }^{\prime} s \\
& t_{r n s} \geq t t_{k u s}
\end{aligned}
$$

Else

go to step 3

End if

$$
\begin{aligned}
& \text { Else } \\
& \text { If } B_{S}<A_{s} \text { then } \\
& B_{\text {rno } ~} s \leq C_{K c} \\
& \alpha_{r n o}{ }_{s}=0 \quad / / \text { no empty bins in the inbound direction } \\
& t_{\text {rlos }} \geq\left(\beta_{\text {rnos }} / \text { Hrate }_{\mathrm{S}}\right)+\text { Hstart }_{\mathrm{S}} \\
& t_{r+1 \text { nos }} \geq t_{\text {rnos }}+\left(\beta_{\text {rnos }} / \text { Hrate }_{\mathrm{S}}\right)+\text { Hstart }_{\mathrm{S}} \\
& t_{r n s} \geq t t_{k u s} \\
& \alpha_{\text {rno }{ }^{-}{ }_{s}}+B_{\text {rno }{ }^{-} s} \leq C_{s} \\
& B_{k r}=B_{k r}-B_{k r o ' s u} \\
& B_{s}=B_{s}+B_{\text {rno } s}
\end{aligned}
$$

Else

go to step 3

End if

Else

End if;

$\alpha_{r n o}{ }_{s}=0$

$B_{\text {rno }{ }^{\prime} s}=0$

go to step 3

End if;

End.

\subsubsection{Infield Road Scheduling (IFRS) Algorithm}

The Infield and Factory Road Scheduling (IFRS) Algorithm integrates factory road scheduling system and infield transport system as shown in Figure 5. Factory road transport system from pads and mill uses big truck using 2 bins (B-Double) with fleet size 20 tonnes per bin, while the infield transport system between harvesting areas and pads uses small trucks with one bin fleet size ( 8 tonnes or 5 tonnes).

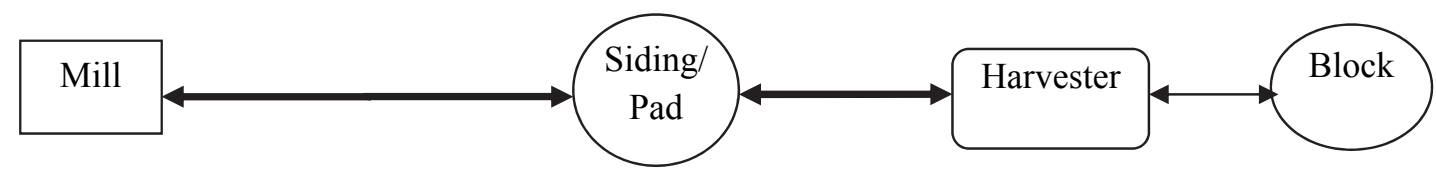

Fig. 5. Factory Road/Infield transport systems 
Select Truck $k$; $k \in K$

Set the Truck capacity $e_{k}$ and $f_{k}$

Select run $u$; $u \in U_{k}$

Select siding $s ; s \in S \quad$ // step 3

Select pad p; $p \in P \quad$ // step 4

Set the siding capacity; $y_{S}$

Set the siding Allotment; $A_{s}$

Delivers full to siding $s$ by truck $k$ at run $u ; z_{k u s} / /$ at the beginning of the system $z_{k u s}=0$

Collect empty from siding s by truck $k$ at run $u ; l_{k u s}$; //at the beginning of the system $l_{k u s}$

$$
\text { If } z_{\text {kus }} \leq A_{s} \text { then }
$$$$
z_{\text {kus }} \leq e_{r}
$$$$
z_{k u s}+l_{k u s} \leq y_{s}
$$$$
z_{s}=z_{s}+z_{k u s}
$$$$
{ }^{t} t_{k 1 s} \geq\left(z_{k u s} / \text { Hrate }_{\mathrm{s}}\right)+\text { Hstart }_{\mathrm{s}}
$$$$
t t_{k+1 u s} \geq t t_{k u s}+\left(z_{k u s} / \text { Hrate }_{\mathrm{S}}\right)+\text { Hstart }_{\mathrm{s}}
$$$$
t_{r n s} \geq t t_{k u s}
$$

Else

go to step 3

End if

$$
\begin{gathered}
\text { Else } \\
\text { If } l_{s}<A_{s} \text { then } \\
l_{k u s} \leq C_{K c} \\
z_{k u s}+l_{k u s} \leq C_{s} \\
l_{s}=l_{s}+l_{k u s} \\
t t_{k l_{s}} \geq\left(l_{k u s} / \text { Hrate }_{\mathrm{s}}\right)+\text { Hstart }_{\mathrm{s}} \\
t t_{k+1 u s} \geq t t_{k u s}+\left(l_{k u s} / \text { Hrate }_{\mathrm{s}}\right)+\text { Hstart }_{\mathrm{s}} \\
t_{r n s} \geq t t_{k u s}
\end{gathered}
$$$$
l_{s}=l_{s}+l_{k u s}
$$

go to step 3

Else

End if

Else

End if;

$\alpha_{r n o}{ }^{\prime} s=0$

$B_{\text {rno }{ }^{\prime} s}=0$

go to step 3

End if;

End.

\subsubsection{Harvester Allocation Optimisation (HAO) algorithm}

In the sugarcane harvesting system, each harvester serves several blocks or farms to satisfy the daily allotment requirement. The harvested crop transported is transported to a siding $r$ for eventual transportation by truck or train to the mill and biorefinery. The $\boldsymbol{H} \boldsymbol{A} \boldsymbol{O}$ algorithm was developed to build Harvester/block/siding assignment for all harvesters in the system the idea of neighbourhood change. Active siding (with harvester) neighbourhoods are considered to create new paths for the harvesting period through the sugarcane rail network, see Fig. 6. 


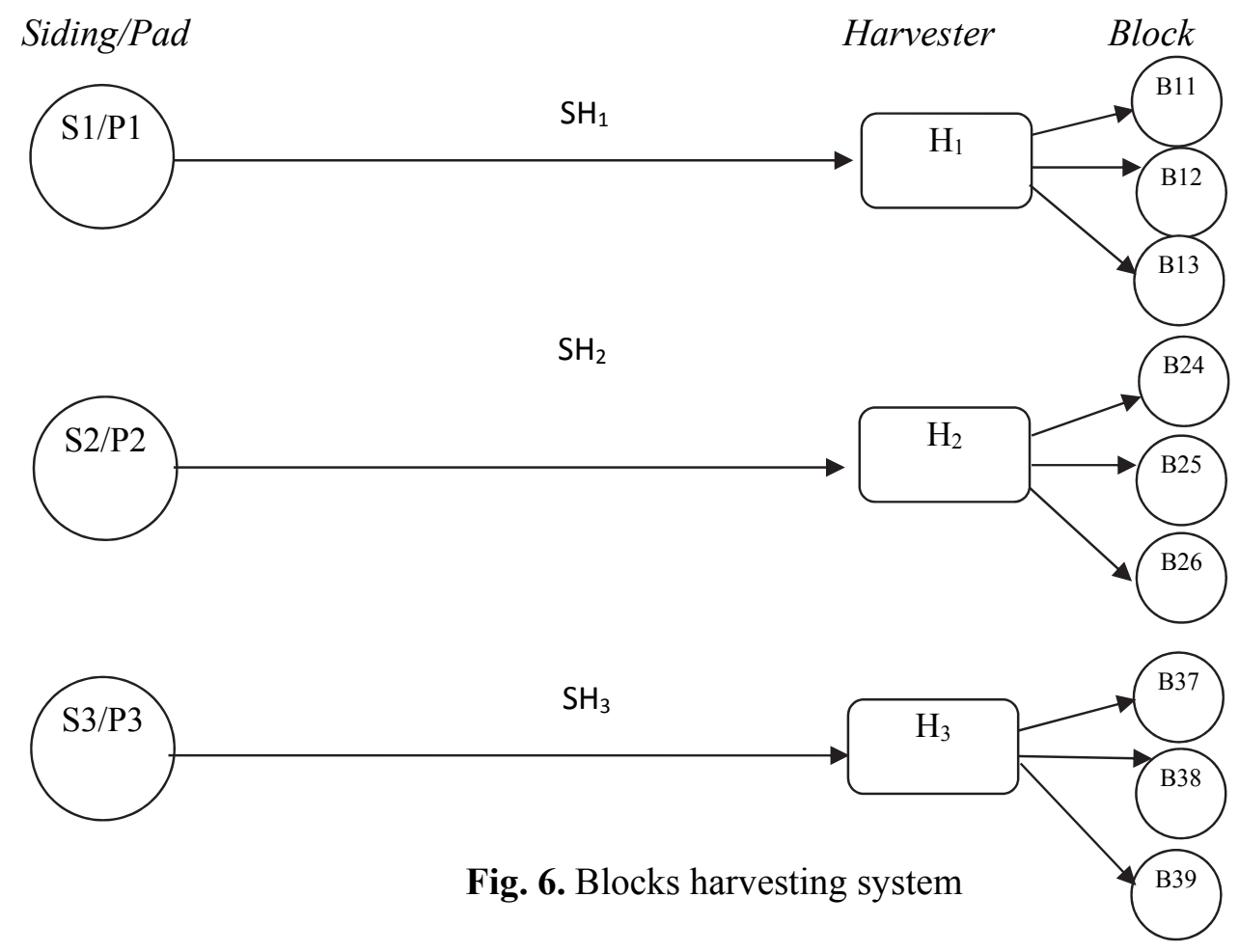

This algorithm includes the following main steps:

\section{Begin}

Step 1 Construct the harvesters list $(1,2,3 \ldots H)$ For the current harvesting season

Step 2 Construct the sidings list $(1,2 \ldots S)$ with its allotment $A_{s}$

Step 3 Set the average distance list between the sidings and harvesters

Step 4 Assigning each harvester for a siding using shortest distance from the harvester and pad siding.

Step 5 Set the priority list of harvesters to be served using two main criteria

\subsection{Cane age}

5.2 Daily allotment

Step 6 While total deliveries and collections $<=$ total daily allotment

6.1 Assigning each harvester in the priority list to closest siding

6.2 Completing allotment (delivers and collections) of each harvester

6.3 Removing the selected sidings and harvesters form the list

End.

6.4 Updating the siding and harvester lists

\subsubsection{Harvester Siding/Pad Blocking (HPB) Algorithm}

Harvester Pad/Siding blocking algorithm has been developed to assign several harvesters to specific siding/pad points according to shortest distance. This can reduce the total operating time and accordingly the associated costs. Fig. 7 shows a small sector of assigning several harvesters with two siding/pad points considering start time and finish time of each harvester to avoid conflict times or overlapping times. 


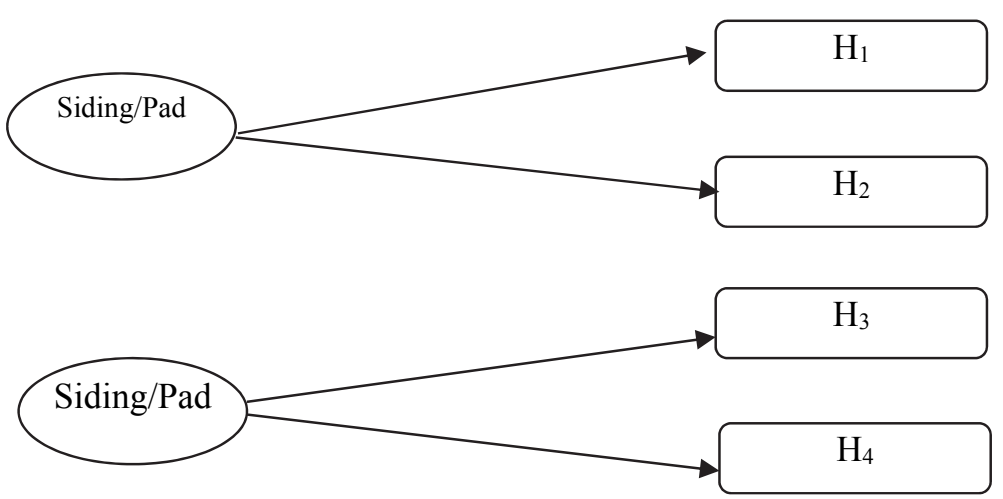

Fig. 7. Harvester Pad/Siding system

The main procedures have been detailed below

Begin

Step 1 Construct the harvesters list (1, 2, 3, H) for the current harvesting season

Step 2 Construct the sidings list $(1,2 \ldots S)$ With its allotment $A_{S}$

Step 3 Set the distance list between the sidings and harvesters

Step 4 Assigning each harvester for a siding using shortest distance from the harvester and pad siding.

Step 5 Set the priority list of harvesters to be served using two main criteria

3.1 Cane age

3.2 Daily allotment

Step 6 While total delivers and collections $<=$ total daily allotment

6.1 Assigning each harvester in the priority list to closest siding

6.2 Completing allotment (delivers and collections) of each harvester

6.3 Removing the selected sidings and harvesters form the list

End

6.4 Updating the siding and harvester lists

\section{Experimental Results}

\subsection{A Rail Transport Case Study}

The proposed algorithms have been tested in a real case study that has been detailed in Appendix A, where Table A1 shows the rail section number and the distance between all network sections. Additionally, each rail section that has been used as a delivery and collection point is called a siding, where the empty and full bins are stored separately in each siding. This siding has two types of capacities, empty capacity (maximum number of empty bins that can be stored in this siding) and full capacity (maximum number of full bins that can be stored in this siding). Table A2 shows the total number of locomotives that has been used to produce the optimised locomotive scheduler, where each locomotive is described by two types of capacities (with full and empty bins) and average speed per hour.

Scheduler for three days has been produced including daily allotment for each harvester. The supply chain of empty and full bins of cane between harvesting points and mill for three days has been figured out in Tables 1, 2 and 3, and Figures 11, 12, and 13. Table 1 shows the delays of collection full bins from several sidings within day 1 . 
Table 1

Delays of crop collections from several sidings in day 1

\begin{tabular}{ccccccc}
\hline Day Index & Siding Index & Allotment in bins & Harvesting Rate & Target Time & Finish Time & Delays in hours \\
\hline 1 & 85 & 124 & 13.433 & 13.231 & 22.11667 & 11.11667 \\
1 & 55 & 96 & 12.581 & 12.63056 & 19.65 & 5.716667 \\
1 & 62 & 70 & 11.194 & 12.25335 & 17.28333 & 5.033333 \\
1 & 61 & 108 & 12.222 & 12.83652 & 17.7 & 1.616667 \\
1 & 67 & 144 & 14.754 & 13.76007 & 18.11667 & 7.633333 \\
1 & 99 & 112 & 10.312 & 14.86113 & 18.83333 & 6.083333 \\
1 & 91 & 104 & 12.281 & 12.46837 & 16.16667 & 3.7 \\
1 & 42 & 134 & 12.712 & 14.04122 & 16.56667 & 3.466667 \\
1 & 19 & 126 & 12.264 & 16.27397 & 17.9 & 1.133333 \\
1 & 17 & 140 & 13.208 & 15.59964 & 17.2 & 0 \\
1 & 32 & 96 & 11.875 & 12.58421 & 13.56667 & 0 \\
1 & 34 & 118 & 12.667 & 13.31554 & 13.41667 & 0 \\
1 & 66 & 30 & 14.754 & 6.033347 & 6.016667 & 0 \\
1 & 86 & 52 & 13.433 & 7.871064 & 7.85 & 0 \\
1 & 16 & 107 & 12.459 & 12.08817 & 12.06667 & 0 \\
1 & 20 & 24 & 12.264 & 7.956947 & 7.933333 & 0 \\
1 & 11 & 82 & 11.972 & 11.34932 & 11.31667 & 0 \\
1 & 49 & 32 & 4.561 & 10.01601 & 9.983334 & 0 \\
1 & 82 & 84 & 10.5 & 11 & 10.96667 & 0 \\
1 & 45 & 84 & 10 & 13.4 & 13.31667 & 0 \\
\hline
\end{tabular}

Figure 8 shows number of empty bins (red graph) and full bins (green graph) at mill in the first day of harvesting, where a specific allotment is required to be transported from harvesting points to mill. From Figure 8 , we note that there is no shortage in the number of empty and full bins in the first day, where number of bins at mill is above zero. The system started with 670 full bins and 730 empty bins, where the full bins at the beginning of the system means the number of empty bins at harvesters that has been distributed previous night as inventory. The total number of bins that have been used in the system equal 1400 bins. The number of bins that has been used at the rest of day is less than the initial bins number.

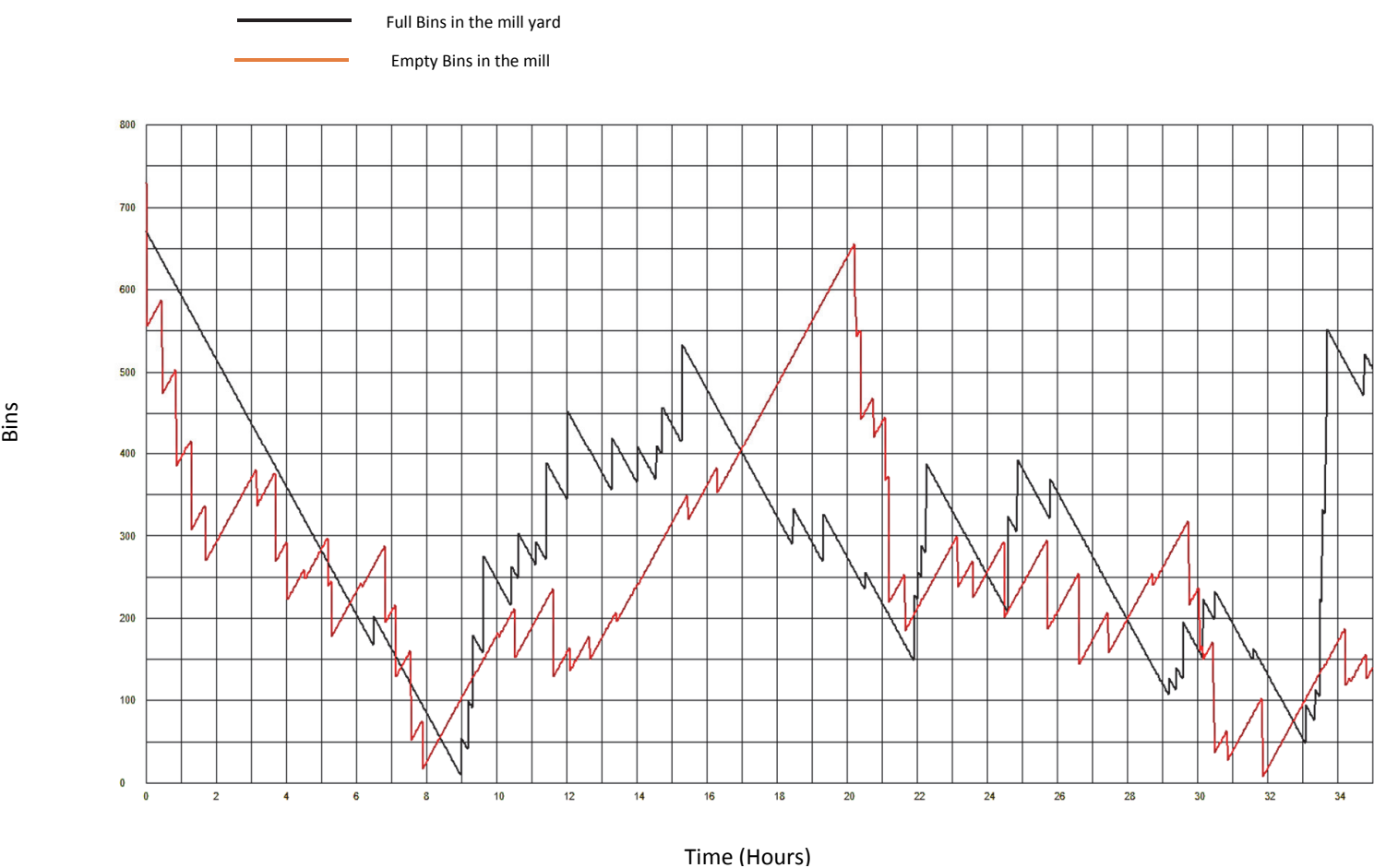

Fig. 8. Empty and full bins at Mill in the first day 
Table 2 shows the collection delays for the second day where the maximum delays was 10.366 hours for siding 67. Fig. 9 shows the number of empty and full bins at mill that has been used in the second day.

Table 2

Delays of crop collections from several sidings in day 2

\begin{tabular}{ccccccc}
\hline Day Index & Siding Index & Allotment in bins & Harvesting Rate & Target Time & Finish Time & Delays in hours \\
2 & 86 & 52 & 13.433 & 31.87107 & 39.46667 & 7.6 \\
2 & 42 & 134 & 12.712 & 38.04122 & 47.2 & 14.26667 \\
2 & 67 & 144 & 14.754 & 37.76006 & 43.9 & 10.36667 \\
2 & 82 & 84 & 10.5 & 35 & 38.6 & 3.6 \\
2 & 34 & 118 & 12.667 & 37.31554 & 38.93333 & 0 \\
2 & 55 & 96 & 12.581 & 36.63055 & 37.96667 & 2.1 \\
2 & 17 & 140 & 13.208 & 39.59964 & 40.86666 & 0 \\
2 & 66 & 30 & 14.754 & 30.03335 & 31.3 & 1.266667 \\
2 & 32 & 96 & 11.875 & 36.58421 & 37.7 & 0 \\
2 & 62 & 70 & 11.194 & 36.25335 & 37.33333 & 1.1 \\
2 & 61 & 108 & 12.222 & 36.83652 & 37.81667 & 0.983333 \\
2 & 19 & 126 & 12.264 & 40.27397 & 40.81667 & 0.05 \\
2 & 45 & 84 & 10 & 37.4 & 37.4 & 0.016667 \\
2 & 91 & 104 & 12.281 & 36.46837 & 36.45 & 0 \\
2 & 16 & 107 & 12.459 & 36.08817 & 36.06667 & 0 \\
2 & 20 & 24 & 12.264 & 31.95695 & 31.93333 & 0 \\
2 & 99 & 112 & 10.312 & 38.86113 & 38.83333 & 0 \\
\hline
\end{tabular}

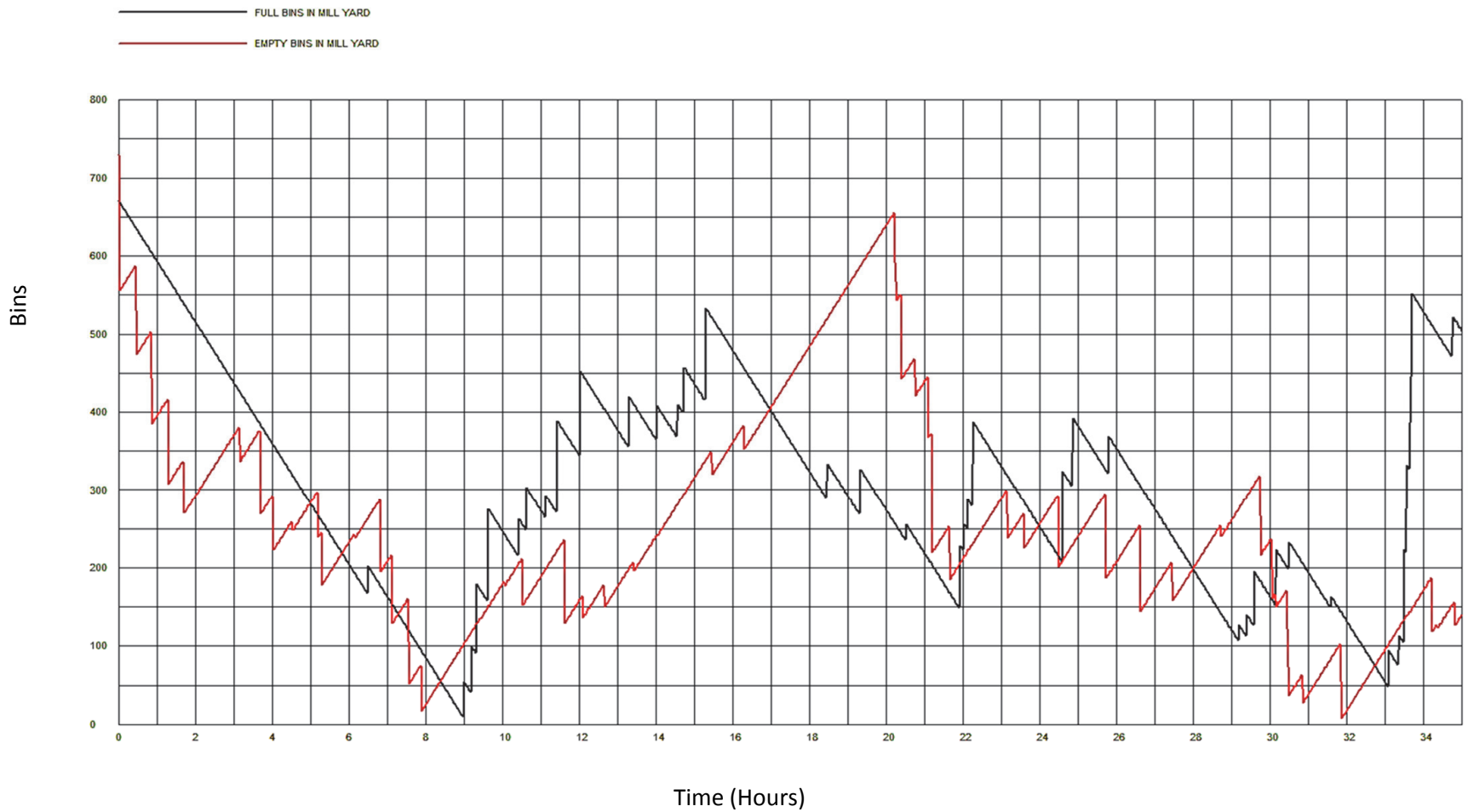

Fig. 9. Empty and full bins at Mill in the second day

Table 3 shows the delays of collections during the third day where the maximum delays is 6.11 for siding 45. Fig. 10 shows the empty and full bins at mill that has been used to transport the third day's allotment of sugarcane. 
Table 3

Delays of crop collections from several sidings in day 3

\begin{tabular}{ccccccc}
\hline Day Index & Siding Index & Allotment in bins & Harvesting Rate & Target Time & Finish Time & Delays in hours \\
\hline 3 & 45 & 100 & 10 & 63 & 69.1 & 6.116667 \\
3 & 49 & 82 & 4.561 & 68.97852 & 75.06667 & 6.1 \\
3 & 55 & 12.581 & 56.02043 & 61.66667 & 5.683333 \\
3 & 54 & 31 & 13.44467 & 57.46273 & 62.9 & 5.45 \\
3 & 66 & 14.754 & 54.60112 & 56.8 & 2.2 \\
3 & 61 & 93 & 12.222 & 59.60923 & 61.33333 & 0.333333 \\
3 & 19 & 92 & 12.264 & 61.50163 & 62.4 & 0 \\
3 & 17 & 153 & 13.208 & 64.58389 & 65.3 & 0 \\
3 & 29 & 38 & 12.66667 & 55.5 & 55.48333 & 0 \\
3 & 2 & 16 & 12.459 & 52.78421 & 52.76667 & 0 \\
3 & 11 & 101 & 11.972 & 60.93635 & 60.91667 & 0 \\
3 & 91 & 85 & 12.281 & 58.92126 & 58.9 & 0 \\
3 & 34 & 116 & 12.667 & 61.15765 & 61.13334 & 0 \\
3 & 86 & 31 & 13.433 & 54.80775 & 54.78333 & 0 \\
3 & 32 & 48 & 11.875 & 56.5421 & 56.51667 & 0 \\
3 & 100 & 110 & 15.323 & 58.17875 & 58.15 & 0 \\
3 & 16 & 93 & 12.459 & 58.96449 & 58.93333 & 0 \\
\hline
\end{tabular}

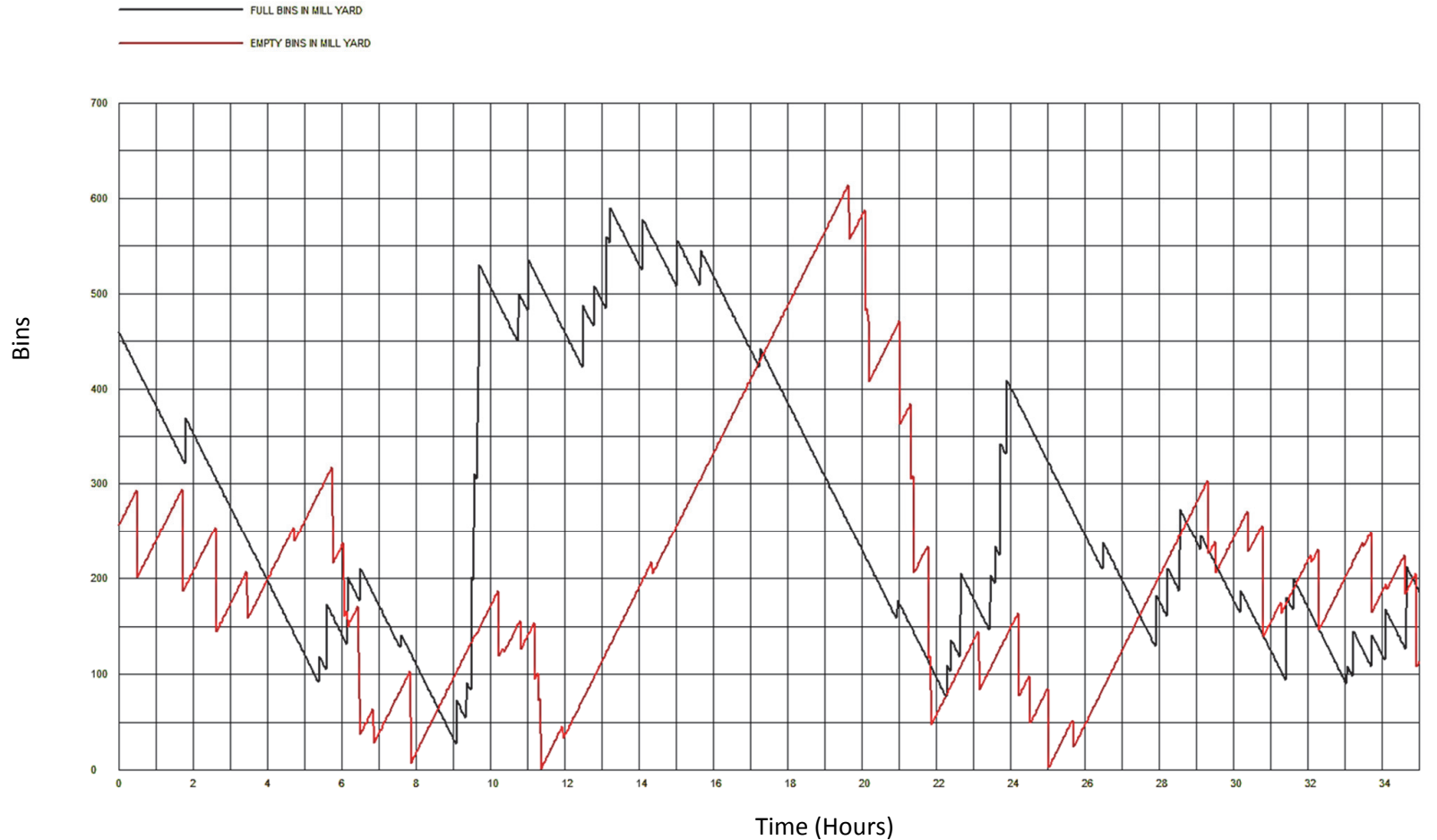

Fig. 10. Empty and full bins at Mill in the Third day

The efficient performance of the transport system can be measured by keeping the supply chain of empty and full bins of cane between harvesting points and mills without any interruptions and delays. Additionally, the stocks rate of empty and full bins at mill is considered where the transport system works through limited number of resources from bins and Locomotives. This prevent any work interruptions of mill and keep empty bins supply for harvesters. A continuous supply chain of bins between harvesting points and mill has been satisfied using the proposed methodology as shown previously in Figs. (10-12).

Trains scheduling is produced for three days using 6 trains with 100 rail sections. Fig. 11 shows the train scheduling with makespan, 4915 minutes, total number of runs sums up to 134 trips and the total 
operating time is $219.5 \mathrm{~h}$. The deliveries and collections number of full and empty bins have been shown in Fig. 12, where green number is full collected bins and red number is empty delivered bins. Operating times inbound and outbound directions have been detailed in Fig. 13 with showing the waiting time at each section.

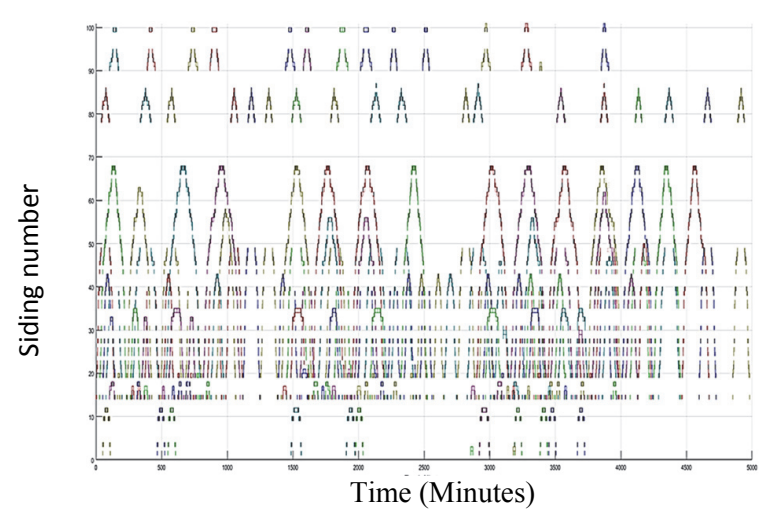

Fig. 11. Gantt chart of 6 trains scheduling with $27 \mathrm{~km} / \mathrm{h}$

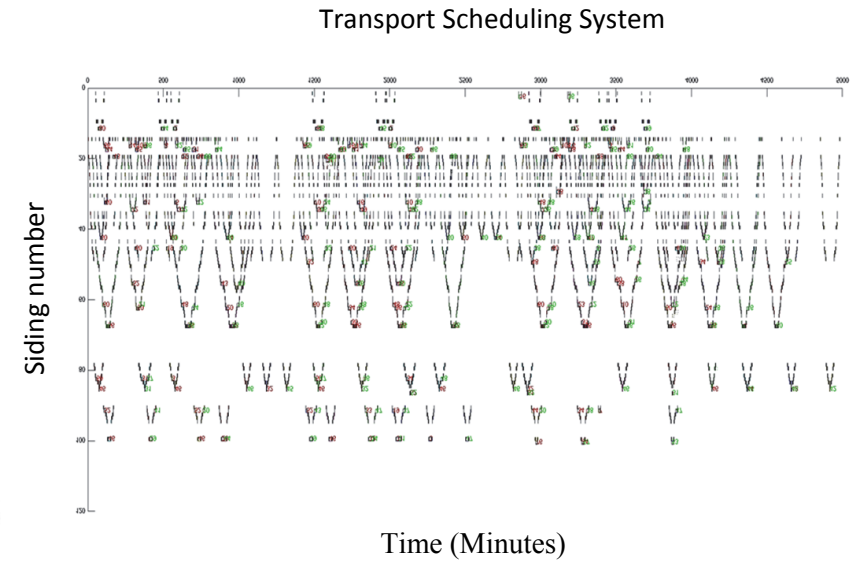

Fig. 12. Delivery and collections at marked sidings within several trips

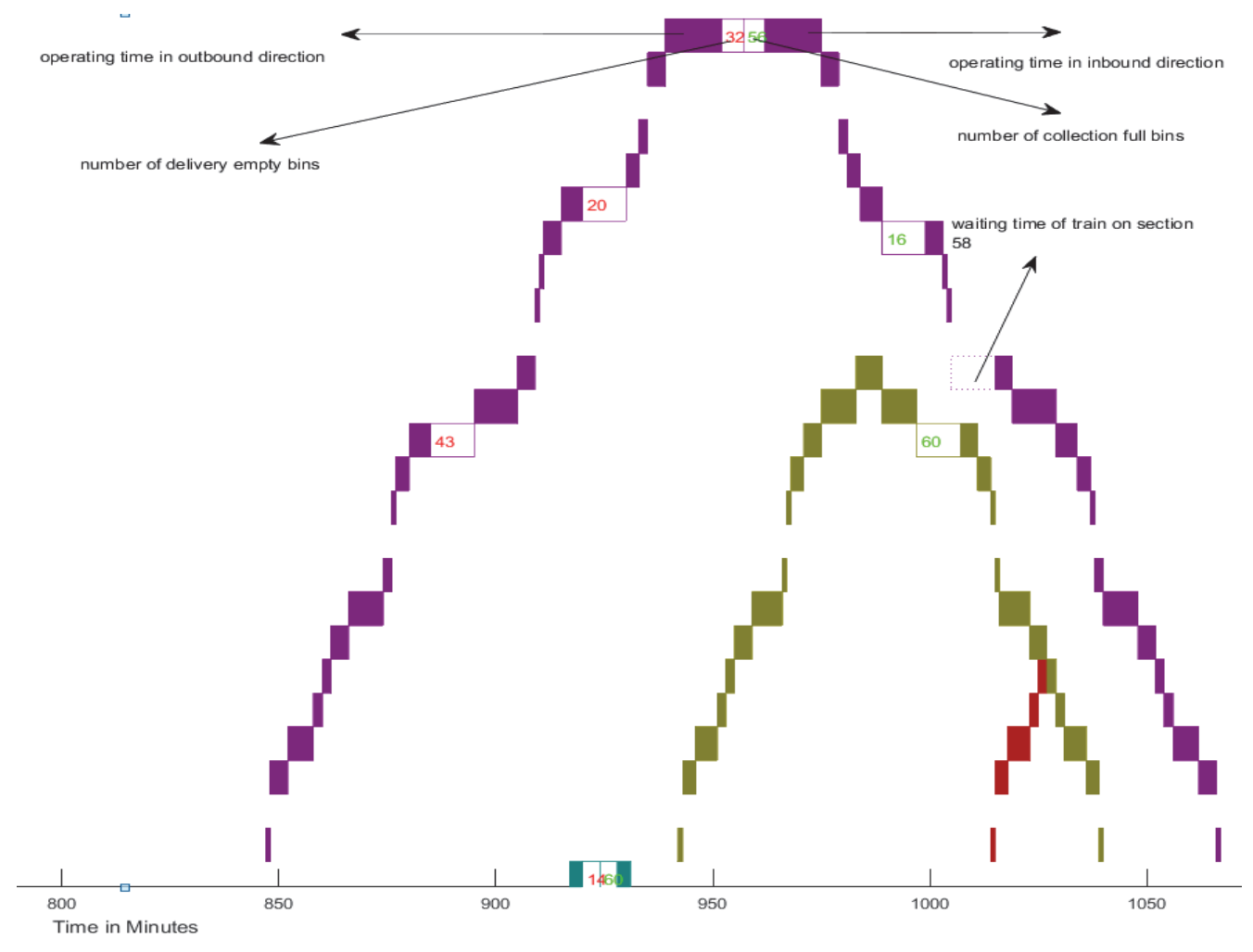

Fig. 13. Close up of train scheduling showing delivery and collection bins

Fig. 14 concludes the total operating time for the three days and the number of trips that have been used by each locomotive to satisfy the total allotments of all harvesters. In Figure 15, the trips distribution for each locomotive has been shown and concluded. 


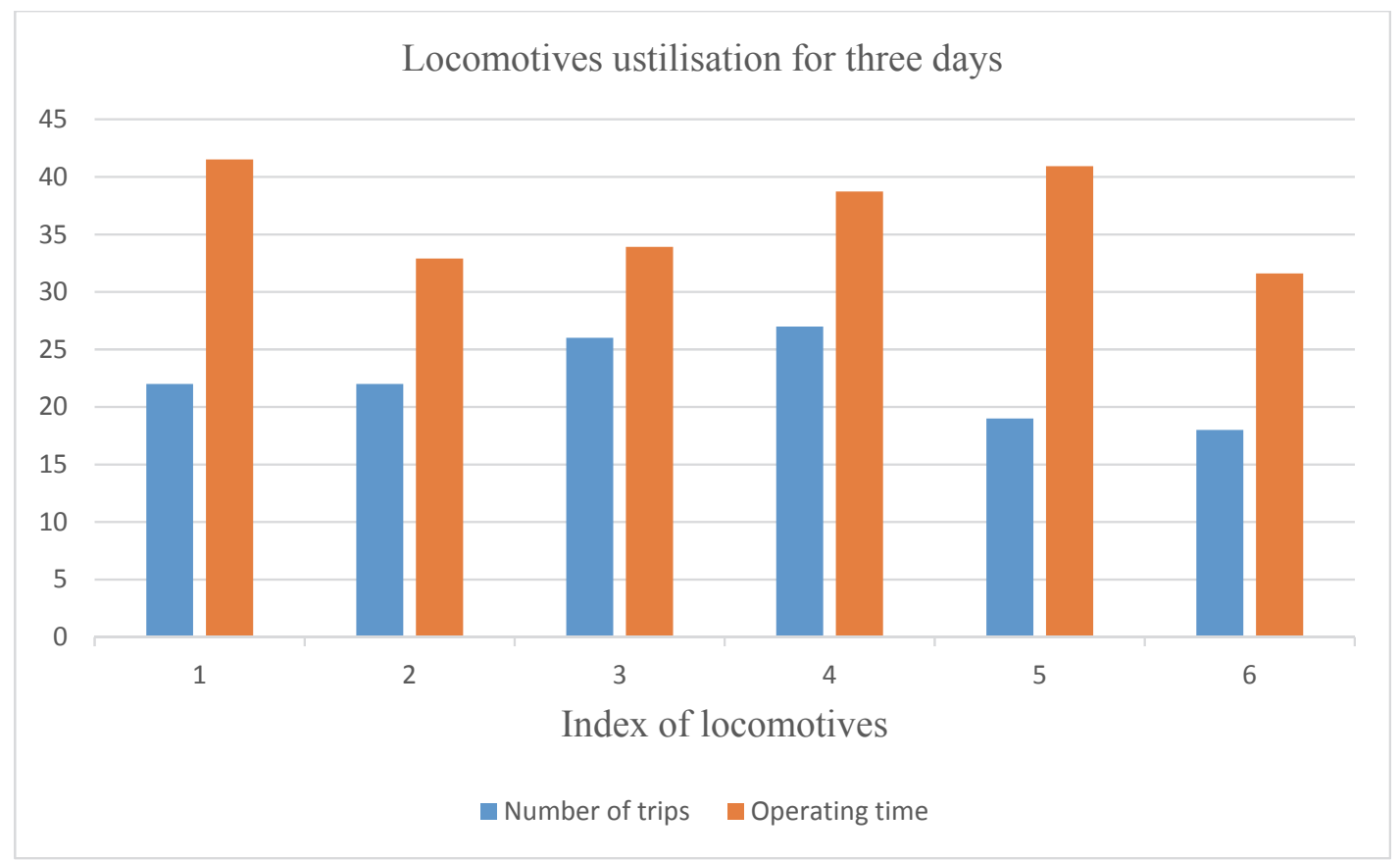

Fig. 14. Operating time for the three days schedule using 6 locomotives

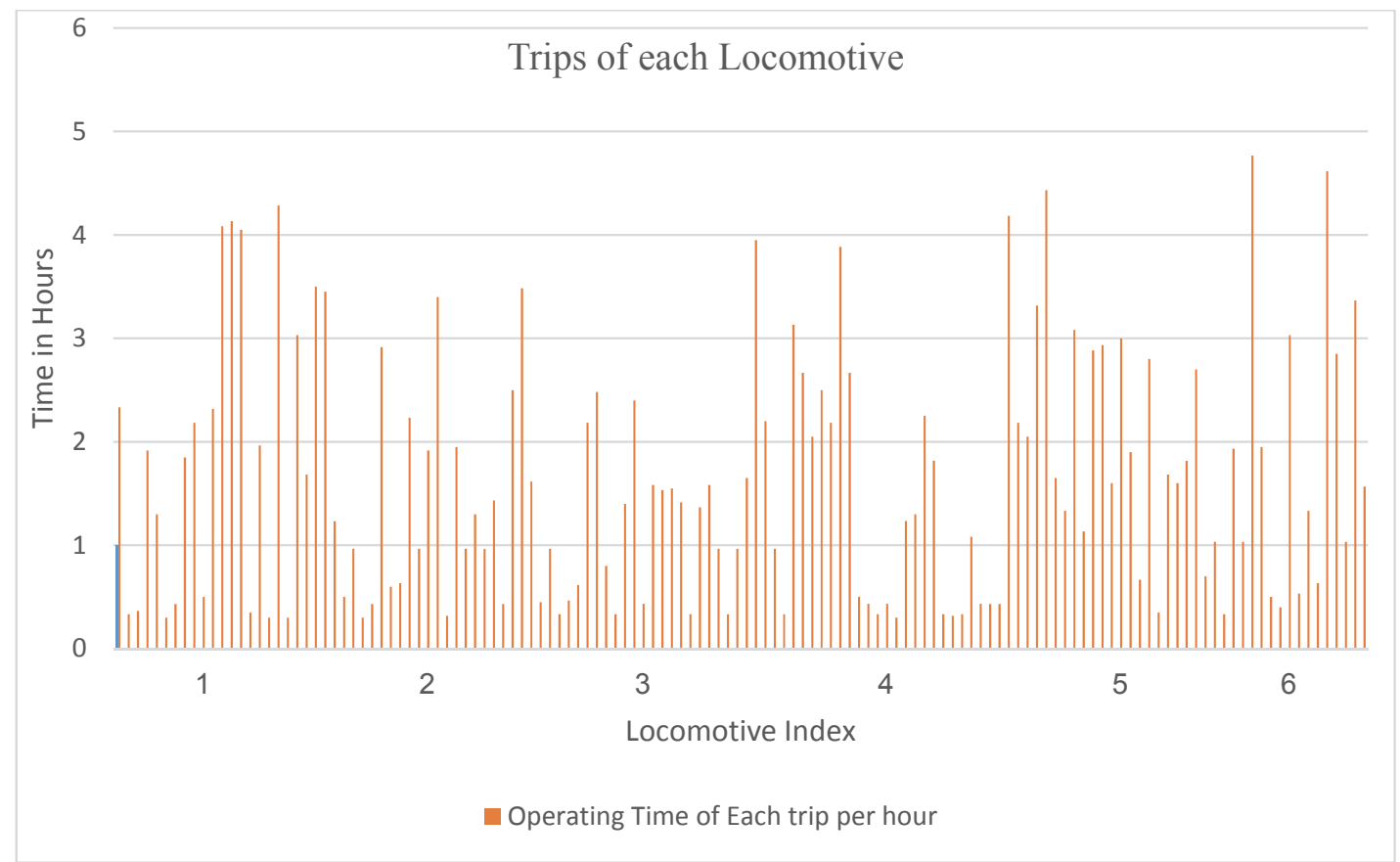

Fig. 15. Trips distribution for the 6 locomotives during three days

The proposed methodology has been applied for the whole season of sugarcane harvesting and delivery of both cane and trash from harvesting areas to mill. In this system the total operating time has greatly improved. Figure 16(a) shows the total operating time and the total deliveries without applying the proposed scheduling methodology, while Figure $16 \mathrm{~b}$ shows the values with applying the scheduling approach. The total cane delivered captioned in blue, while the processed cane is captured is orange .From Figure 16 (b), the total cane delivered is 893086 tonnes and delivered in 5286 Hours without applying scheduling approach, while the total cane delivered and trash in figure 16(c) 1025470 tonnes 
and delivered in 3504 Hours using the proposed scheduling approach which is a great improvement in terms of total operation time resource utilisation.

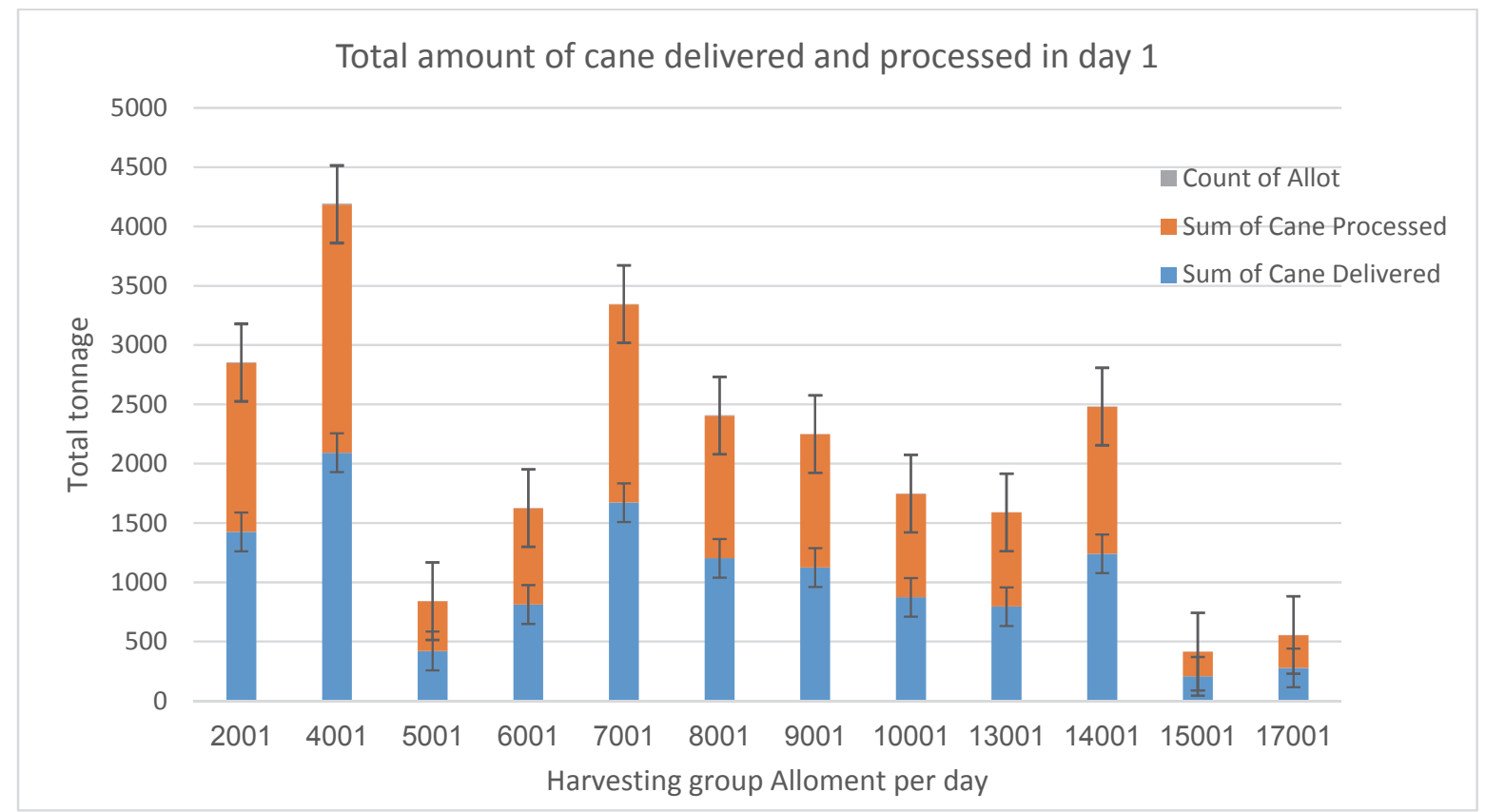

Fig. 16 (a). Total amount of cane delivered and processed in day number 1 per harvesting group

Further, Figure 16 (a) above shows a graph of activities in a sugar factory for one day operation, which from the simulation a total $12,136.59$ tonnes of cane were delivered and processed. The sugar factory is assumed to operates at a rate of 600 tonnes/hour (crushing rate), continuously for 24 hours. Therefore, assuming an efficiency of $90 \%$ for the factory, the total amount of tonnage required per day (24 hours) continuous crushing

Factory requirement $=600$ tonnes $* 24$ hours $* \frac{90}{100}$ (efficiency)

Loss of crushing efficiency $\left(\rho_{\text {loss }}\right)$ therefore is equal to

$\rho_{\text {loss }}=\left\{\frac{600 \text { tonnes } * 24 \text { hours } * \frac{90}{100}(\text { eff })-600 \text { tonnes } * 24 \text { hours } * \frac{90}{100}(\text { eff })}{\left[600 \text { tonnes } * 24 \text { hours } * \frac{90}{100}(\text { efficiency })\right]}\right\} * 100$

$\rho_{\text {loss }}=90 \%-84.28188 \%=5.71812 \%$ Loss

$\rho_{\text {loss }}=5.71812 \%$, which can be corrected, by proper scheduling of transport and harvesting system as shown in Fig. 16(c). 


\section{Factory cane accumulation}

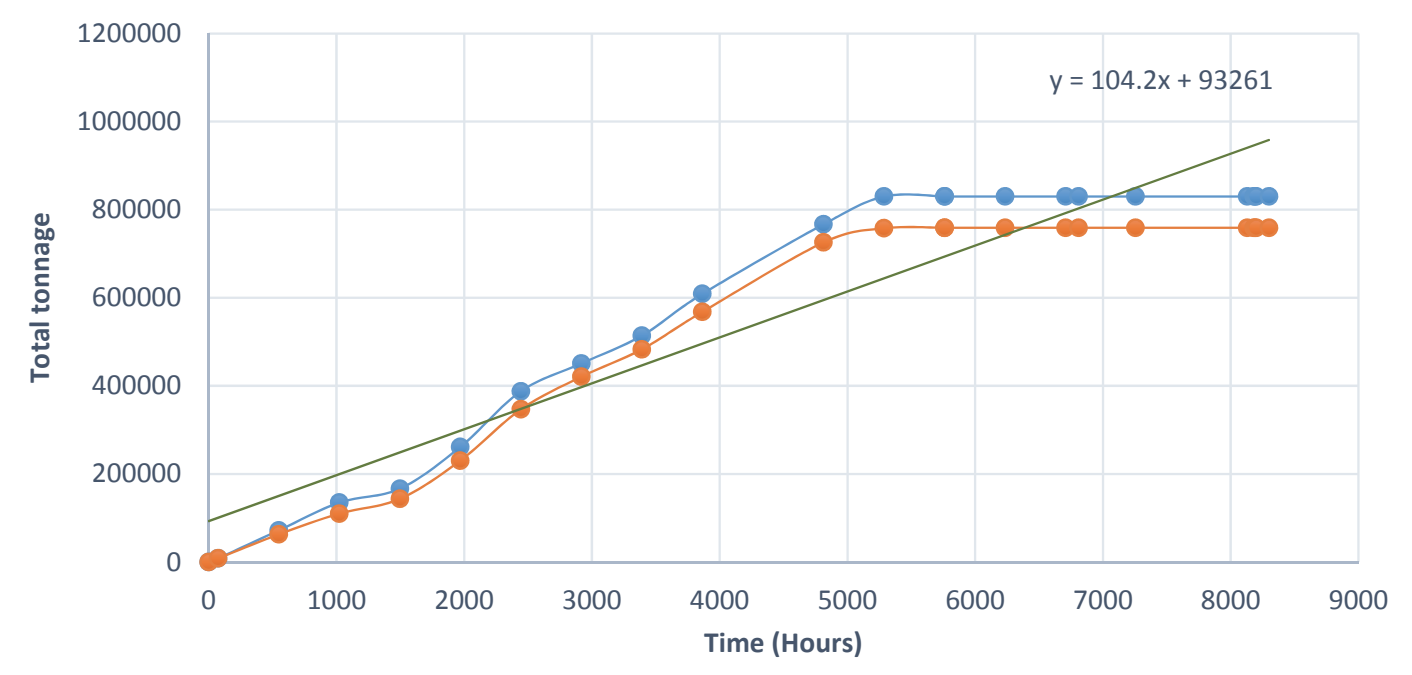

Fig. 16 (b). The operating time and total deliveries without scheduling theory

Fig. 16 (a) depicts a system without scheduling, where at the start of the crushing period (day 1), a total of 94,000 tonnes were delivered to the factory per hour, which point to the fact that most of the time the factory would run out of cane, and would require longer period to finish the operation of harvesting, transport and processing of cane to produce bagasse and other product .This however, is in sharp contrast to the expectation of an ideal system, where a total of 14400 tonnes is required to guarantee continuous crushing.

Fig. 16(c), on the other hand from the line of best fit, at the start of the season, approximately 535224 tonnes are delivered per hour (Y- Intercept) on the graph, thus slightly meeting factory requirements, which in terms of efficiency is approximately $89.204 \%$, which is within the margin of error of an efficient system (90\%), for this case .Scheduling subsequently has improved the operational time of the whole system, and ensured maximum utilisation of the resources thus saving on time and cost

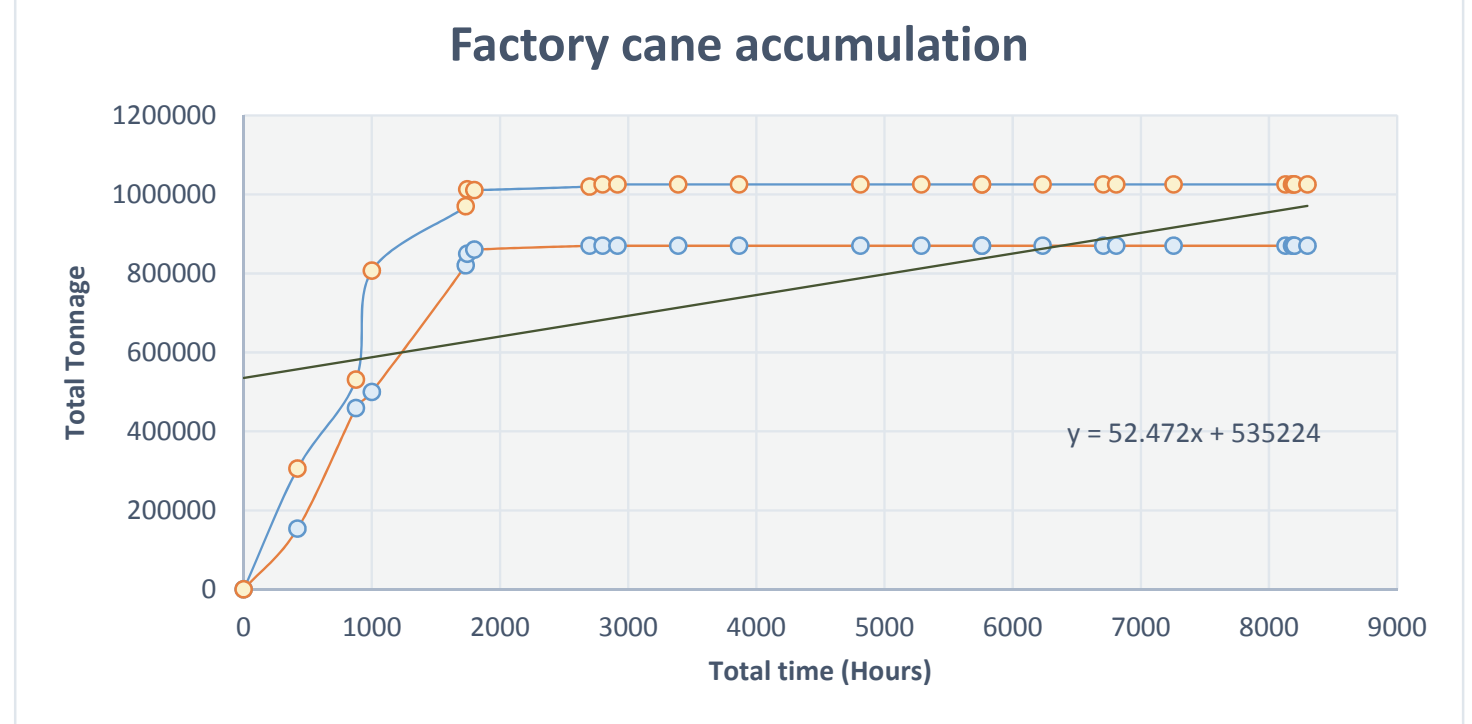

Fig. 16 (c). The operating time and total deliveries with scheduling theory 


\section{Conclusion}

Cane and cane residue transport systems using both rail and road networks play a vital role in the Australian bio-energy supply chain. Delivery and collection times have a high impact on optimising bioenergy production and consequently the associated costs. Constraint programming approach has been introduced with adapted Limited Discrepancy Search (LDS) to optimise the delivery and collection times through the transport network, where the cane and cane residue has been taken from harvesting points to siding or pad points and then transported to mill. The surplus bagasse (a by-product of the crushed cane) is stored at the mill, and is transported later to bio-refinery stations to produce bioenergy.

The constraint programming approach focused on satisfying the proposed model constraints were involved in harvesting operations, transport operations and milling operations. The LDS has been used as search tree that provides a solution with each node (delivery or collection points). The proposed daily trips have been constructed to serve the harvesting points and mills. This numerical case study (based on historical data) indicates that the modelled system has the potential of improving the operational time and in effect save on cost of operation and improve of equipment utilisation.

\section{References}

Asikainen, A., Liiri, H., Peltola, S., Karjalainen, T., \& Laitila, J. (2008). Forest energy potential in Europe (EU27). Finnish Forest Research Institute, Vantaa.

Bookbinder, J. H., \& Desilets, A. (1992). Transfer optimization in a transit network. Transportation Science, 26(2), 106-118.

Chen, C. W., \& Fan, Y. (2012). Bioethanol supply chain system planning under supply and demand uncertainties. Transportation Research Part E: Logistics and Transportation Review, 48(1), 150-164.

De Meyer, A., Cattrysse, D., Rasinmäki, J., \& Van Orshoven, J. (2014). Methods to optimise the design and management of biomass-for-bioenergy supply chains: A review. Renewable and Sustainable Energy Reviews, 31, 657-670.

Faaij, A., Van Ree, R., Waldheim, L., Olsson, E., Oudhuis, A., Van Wijk, A., ... \& Turkenburg, W. (1997). Gasification of biomass wastes and residues for electricity production. Biomass and Bioenergy, 12(6), 387-407.

Harvey, W. D., \& Ginsberg, M. L. (1995, August). Limited discrepancy search. In IJCAI (1) (pp. 607615).

Hassuani, S. J., Da Silva, J. E. A. R., \& Neves, J. L. M. (2005). Sugarcane trash recovery alternatives for power generation. In Proc. ISSCT (Vol. 25).

Henrich, E., Dahmen, N., \& Dinjus, E. (2009). Cost estimate for biosynfuel production via biosyncrude gasification. Biofuels, Bioproducts and Biorefining, 3(1), 28-41.

Hess, J. R., Wright, C. T., \& Kenney, K. L. (2007). Cellulosic biomass feedstocks and logistics for ethanol production. Biofuels, Bioproducts and Biorefining, 1(3), 181-190.

Hobson, P. A., \& Dixon, T. F. (1998). Gasification technology-prospects for large-scale. In Proc. Aust. Soc. Sugar Cane Technol (Vol. 20, pp. 1-9).

Hobson, P. A., \& Wright, P. G. (2002). An Extended Model Of The Economic Impact Of Extraneous Matter Components On The Sugar Industry.

Hobson, P. A., Dixon, T. F., Wheeler, C., \& Lindsay, N. (2003). Progress in the development of bagasse gasification technology for increased cogeneration in the Australian sugar industry. In ProcessdingsAustralian society of sugar cane technology (pp. 60-60). PK Editorial Services; 1999.

Hobson, P. A., Edye, L. A., Lavarack, B., \& Rainey, T. J. (2006). Analysis of bagasse and trash utilization options-SRDC Technical Report 2/2006.

Iakovou, E., Karagiannidis, A., Vlachos, D., Toka, A., \& Malamakis, A. (2010). Waste biomass-toenergy supply chain management: a critical synthesis. Waste Management, 30(10), 1860-1870. 
Mafakheri, F., \& Nasiri, F. (2014). Modeling of biomass-to-energy supply chain operations: applications, challenges and research directions. Energy Policy, 67, 116-126.

Masoud, M., Kozan, E., \& Kent, G. (2011). A job-shop scheduling approach for optimising sugarcane rail operations. Flexible Services and Manufacturing Journal, 23(2), 181-206.

Masoud, M. M. A. A., Kozan, E., \& Kent, G. A. (2012). A new approach to automatically producing schedules for cane railways. In Proceedings of the 34th Conference of the Australian Society of Sugar Cane Technologists (Vol. 34). Australian Society of Sugar Cane Technologists.

Masoud, M. M. A. A., Kozan, E., \& Kent, G. (2015, November). A near Optimal Cane Rail Scheduler under Limited and Unlimited Capacity Constraints. In Proceedings of 21st International Congress on Modelling and Simulation (pp. 1738-1744).

Meyer, J. C., Hobson, P. A., \& Schultmann, F. (2012). The potential for centralised second generation hydrocarbons and ethanol production in the Australian sugar industry. In Proceedings of the Australian Society of Sugar Cane Technologists (Vol. 34).

Nilsson, D., \& Hansson, P. A. (2001). Influence of various machinery combinations, fuel proportions and storage capacities on costs for co-handling of straw and reed canary grass to district heating plants. Biomass and Bioenergy, 20(4), 247-260.

Pernase, S., \& Pekol, A. (2012, September). The Transportation of Sugar Cane in Queensland's Sugar Industry. In Australasian Transport Research Forum 2012 Proceedings (pp. 26-28).

Rapp, M. H., \& Gehner, C. D. (1967). Transfer optimization in an interactive graphic system for transit planning (No. Intrm Rpt.).

Ravula, P. P., Grisso, R. D., \& Cundiff, J. S. (2008). Cotton logistics as a model for a biomass transportation system. Biomass and Bioenergy, 32(4), 314-325.

Rentizelas, A. A., Tolis, A. J., \& Tatsiopoulos, I. P. (2009). Logistics issues of biomass: the storage problem and the multi-biomass supply chain. Renewable and Sustainable Energy Reviews, 13(4), 887894.

Shabani, N., Akhtari, S., \& Sowlati, T. (2013). Value chain optimization of forest biomass for bioenergy production: a review. Renewable and Sustainable Energy Reviews, 23, 299-311.

Sokhansanj, S., Turhollow, A., Cushman, J., \& Cundiff, J. (2002). Engineering aspects of collecting corn stover for bioenergy. Biomass and Bioenergy, 23(5), 347-355.

Sokhansanj, S., Mani, S., Tagore, S., \& Turhollow, A. F. (2010). Techno-economic analysis of using corn stover to supply heat and power to a corn ethanol plant-Part 1: Cost of feedstock supply logistics. Biomass and Bioenergy, 34(1), 75-81.

Thorburn, P. J., Archer, A. A., Hobson, P. A., Higgins, A. J., Sandell, G. R., Prestwidge, D. B., ... \& Juffs, R. (2006). Value chain analyses of whole crop harvesting to maximise co-generation. In PROCEEDINGS-AUSTRALIAN SOCIETY OF SUGAR CANE TECHNOLOGISTS (Vol. 2006, p. 37). PK Editorial Services; 1999.

Vadas, P. A., \& Digman, M. F. (2013). Production costs of potential corn stover harvest and storage systems. Biomass and Bioenergy, 54, 133-139.

Van Dyken, S., Bakken, B. H., \& Skjelbred, H. I. (2010). Linear mixed-integer models for biomass supply chains with transport, storage and processing. Energy, 35(3), 1338-1350.

Van Vliet, O. P., Faaij, A. P., \& Turkenburg, W. C. (2009). Fischer-Tropsch diesel production in a wellto-wheel perspective: a carbon, energy flow and cost analysis. Energy Conversion and Management, 50(4), 855-876.

Wang, J. J., Yang, K., Xu, Z. L., Fu, C., Li, L., \& Zhou, Z. K. (2014). Combined methodology of optimization and life cycle inventory for a biomass gasification based BCHP system. Biomass and Bioenergy, 67, 32-45.

Yue, D., You, F., \& Snyder, S. W. (2014). Biomass-to-bioenergy and biofuel supply chain optimization: overview, key issues and challenges. Computers \& Chemical Engineering, 66, 36-56. 


\section{Appendix A}

Table A1

Rail Transport Network

\begin{tabular}{|c|c|c|c|c|c|c|c|c|c|}
\hline Segment & Section & Distance & Capacity Empty & Capacity Full & Segment & Section & Distance & Capacity & Capacity \\
\hline 1,0 & 1 & 0.48 & 0 & 0 & 33,0 & 58 & 1.48 & 66 & 68 \\
\hline 2,0 & 2 & 0.32 & 60 & 60 & 34,0 & 59 & 0.07 & 58 & 64 \\
\hline 3,0 & 3 & 1.59 & 0 & 0 & 34,0 & 60 & 0.33 & 44 & 54 \\
\hline 4,0 & 4 & 0.98 & 80 & 82 & 34,0 & 61 & 1.21 & 60 & 74 \\
\hline 4,0 & 5 & 1.82 & 0 & 0 & 34,0 & 62 & 1.48 & 50 & 62 \\
\hline 5,0 & 6 & 0.19 & 68 & 68 & 34,0 & 63 & 1 & 0 & 0 \\
\hline 6,0 & 7 & 0.93 & 38 & 38 & 350 & 64 & 0.5 & 0 & 0 \\
\hline 6,0 & 8 & 1.6 & 110 & 110 & 35,1 & 65 & 0.5 & 0 & 0 \\
\hline 7,0 & 9 & 4.22 & 0 & 0 & 36,0 & 66 & 1.07 & 62 & 70 \\
\hline 8,0 & 10 & 0.27 & 72 & 68 & 36,0 & 67 & 3.81 & 56 & 63 \\
\hline 9,0 & 11 & 2.03 & 80 & 80 & 36,0 & 68 & 2.89 & 0 & 0 \\
\hline 10,0 & 12 & 1.68 & 58 & 70 & 37,0 & 69 & 3.23 & 82 & 90 \\
\hline 10,0 & 13 & 2.4 & 52 & 52 & 38,0 & 70 & 0.98 & 56 & 66 \\
\hline 11,0 & 14 & 0.71 & 0 & 0 & 38,0 & 71 & 1.06 & 208 & 208 \\
\hline 12,0 & 15 & 0.66 & 0 & 0 & 38,0 & 72 & 1.16 & 62 & 68 \\
\hline 13,0 & 16 & 0.36 & 66 & 66 & 38,0 & 73 & 1.23 & 50 & 58 \\
\hline 14,0 & 17 & 1.53 & 110 & 110 & 38,0 & 74 & 2.54 & 80 & 82 \\
\hline 14,0 & 18 & 3.13 & 66 & 60 & 38,0 & 75 & 0.24 & 88 & 88 \\
\hline 15,0 & 19 & 1.11 & 64 & 66 & 38,0 & 76 & 2.77 & 212 & 212 \\
\hline 150 & 20 & 0.44 & 28 & 34 & 38,0 & 77 & 2.71 & 80 & 96 \\
\hline 15,0 & 21 & 1 & 0 & 0 & 39,0 & 78 & 1.43 & 58 & 68 \\
\hline 16,0 & 22 & 0.5 & 0 & 0 & 39,0 & 79 & 1.73 & 0 & 0 \\
\hline 16,1 & 23 & 0.5 & 0 & 0 & 40,0 & 80 & 0.22 & 62 & 62 \\
\hline 17,0 & 24 & 0.19 & 74 & 74 & 41,0 & 81 & 1.57 & 26 & 36 \\
\hline 18,0 & 25 & 0.5 & 0 & 0 & 41,0 & 82 & 1.13 & 50 & 56 \\
\hline 18,1 & 26 & 0.5 & 0 & 0 & 41,0 & 83 & 2.49 & 50 & 56 \\
\hline 19,0 & 27 & 1.07 & 0 & 0 & 41,0 & 84 & 0.83 & 0 & 0 \\
\hline 20,0 & 28 & 0.32 & 50 & 50 & 42,0 & 85 & 0.31 & 46 & 46 \\
\hline 20,0 & 29 & 0.01 & 48 & 48 & 43,0 & 86 & 0.71 & 62 & 64 \\
\hline 21,0 & 30 & 0.13 & 0 & 0 & 43,0 & 87 & 2.61 & 0 & 0 \\
\hline 22,0 & 31 & 0.33 & 34 & 34 & 44,0 & 88 & 0.22 & 34 & 34 \\
\hline 22,0 & 32 & 1.4 & 70 & 80 & 45,0 & 89 & 0.17 & 40 & 40 \\
\hline 22,0 & 33 & 1.06 & 66 & 70 & 46,0 & 90 & 0.76 & 52 & 66 \\
\hline 22,0 & 34 & 1.01 & 72 & 82 & 46,0 & 91 & 0.14 & 52 & 66 \\
\hline 23,0 & 35 & 0.5 & 0 & 0 & 46,0 & 92 & 1.75 & 60 & 86 \\
\hline 24,0 & 36 & 0.5 & 0 & 0 & 46,0 & 93 & 1.39 & 54 & 66 \\
\hline 24,1 & 37 & 0.5 & 0 & 0 & 46,0 & 94 & 0.73 & 0 & 0 \\
\hline 25,0 & 38 & 1 & 0 & 0 & 47,0 & 95 & 1.46 & 56 & 62 \\
\hline 26,0 & 39 & 1.9 & 0 & 0 & 47,0 & 96 & 0.15 & 0 & 0 \\
\hline 27,0 & 40 & 1.2 & 94 & 94 & 47,0 & 97 & 0.39 & 62 & 62 \\
\hline 27,0 & 41 & 1.24 & 64 & 68 & 47,0 & 98 & 0.37 & 52 & 52 \\
\hline 27,0 & 42 & 0.99 & 60 & 60 & 48,0 & 99 & 1.5 & 46 & 54 \\
\hline 28,0 & 43 & 0.19 & 126 & 126 & 48,0 & 100 & 0.43 & 76 & 76 \\
\hline 28,1 & 44 & 0.19 & 0 & 0 & & & & & \\
\hline 29,0 & 45 & 1.22 & 60 & 64 & & & & & \\
\hline 29,0 & 46 & 1.94 & 60 & 60 & & & & & \\
\hline 29,0 & 47 & 0.68 & 62 & 78 & & & & & \\
\hline 29,0 & 48 & 0.67 & 44 & 44 & & & & & \\
\hline 30,0 & 49 & 1.3 & 48 & 54 & & & & & \\
\hline 30,0 & 50 & 2.42 & 86 & 88 & & & & & \\
\hline 31,0 & 51 & 0.5 & 0 & 0 & & & & & \\
\hline 31,1 & 52 & 0.5 & 0 & 0 & & & & & \\
\hline 32,0 & 53 & 0 & 86 & 88 & & & & & \\
\hline 32,0 & 54 & 0.95 & 62 & 52 & & & & & \\
\hline 32,0 & 55 & 1.41 & 52 & 60 & & & & & \\
\hline 32,0 & 56 & 2.97 & 64 & 56 & & & & & \\
\hline 32,0 & 57 & 1.1 & 0 & 0 & & & & & \\
\hline
\end{tabular}

Table A2

Locomotives capacity and speed

\begin{tabular}{cccc}
\hline Locomotive Number & Locomotive Full Capacity & Average Speed $(\mathrm{Km} / \mathrm{h})$ & Locomotive Empty Capacity \\
\hline 1 & 120 & 22 & 120 \\
2 & 120 & 22 & 120 \\
3 & 120 & 22 & 120 \\
4 & 110 & 22 & 120 \\
5 & 90 & 18 & 110 \\
6 & 72 & 18 & 110 \\
\hline
\end{tabular}

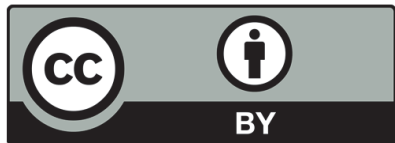

(C) 2018 by the authors; licensee Growing Science, Canada. This is an open access article distributed under the terms and conditions of the Creative Commons Attribution (CCBY) license (http://creativecommons.org/licenses/by/4.0/). 